\title{
The proton pump inhibitor pantoprazole disrupts protein degradation systems and sensitizes cancer cells to death under various stresses
}

\author{
Yu Cao ${ }^{1,2}$, Min Chen 1,2, Dehua Tang ${ }^{1,2}$, Hongli Yan ${ }^{3}$, Xiwei Ding ${ }^{1,2}$, Fan Zhou ${ }^{1,2}$, Mingming Zhang ${ }^{1,2}$, Guifang Xu, \\ Weijie Zhang $\mathbb{1 0}^{4,5}$, Shu Zhang ${ }^{1,2}$, Yuzheng Zhuge ${ }^{1,2}$, Lei Wang ${ }^{1,2}$ and Xiaoping Zou ${ }^{1,2}$
}

\begin{abstract}
Proton pump inhibitors (PPIs) play a role in antitumor activity, with studies showing specialized impacts of PPIs on cancer cell apoptosis, metastasis, and autophagy. In this study, we demonstrated that pantoprazole (PPI) increased autophagosomes formation and affected autophagic flux depending on the $\mathrm{pH}$ conditions. PPI specifically elevated SQSTM1 protein levels by increasing SQSTM1 transcription via NFE2L2 activation independent of the specific effect of PPI on autophagic flux. Via decreasing proteasome subunits expression, PPI significantly impaired the function of the proteasome, accompanied by the accumulation of undegraded poly-ubiquitinated proteins. Notably, PPI-induced autophagy functioned as a downstream response of proteasome inhibition by PPI, while suppressing protein synthesis abrogated autophagy. Blocking autophagic flux in neutral pH condition or further impairing proteasome function with proteasome inhibitors, significantly aggravated PPI cytotoxicity by worsening protein degradation ability. Interestingly, under conditions of mitochondrial stress, PPI showed significant synergism when combined with Bcl-2 inhibitors. Taken together, these findings provide a new understanding of the impact of PPIs on cancer cells' biological processes and highlight the potential to develop more efficient and effective combination therapies.
\end{abstract}

\section{Introduction}

Proteostasis is a necessity for cell survival when facing stress $^{1}$. Two major protein degradation systems have developed to handle these tasks, the ubiquitin-proteasome system (UPS) and the autophagy-lysosome pathway $(\mathrm{ALP})^{2}$. Proteasome inhibition caused poly-ubiquitinated proteins accumulation, and then activated autophagy to eliminate protein aggregates ${ }^{1-6}$. UPS and ALP share common signaling receptors and substrates such as SQSTM1 ${ }^{7}$. Therefore, in the context of proteasome

\footnotetext{
Correspondence: Lei Wang (867152094@qq.com) or

Xiaoping Zou (13770771661@163.com)

'Department of Gastroenterology, Drum Tower Hospital Affiliated to Medical School of Nanjing University, Nanjing, Jiangsu Province, China

${ }^{2}$ Jiangsu Clinical Medical Center of Digestive Disease, Nanjing, China Full list of author information is available at the end of the article. Edited by G. M. Fimia
}

inhibition, the complexity of using SQSTM1 as an autophagy marker should be underscored ${ }^{8,9}$. Besides autophagy, accumulation of unfolded proteins in the endoplasmic reticulum (ER) upon proteasome inhibition, initiates a specialized response known as the unfolded protein response $(\mathrm{UPR})^{10}$. The intensity of UPR reflects the protein overload stress. Once beyond the scope of tolerance, a terminal UPR was provoked and the irreversible damage would be brought to cancer cells under integrated stress ${ }^{11}$.

Mitochondrial permeabilization is controlled by the balance of antiapoptotic and proapoptotic Bcl-2 family proteins, which set the apoptotic threshold ${ }^{12}$. In the case of proteasome inhibition, there would be a complex crosstalk between mitochondria and other organelles, and various regulations of $\mathrm{Bcl}-2$ family proteins ${ }^{13,14}$. Silencing the prosurvival

\section{(c) The Author(s) 2018}

(c) (i) Open Access This article is licensed under a Creative Commons Attribution 4.0 International License, which permits use, sharing, adaptation, distribution and reproduction in any medium or format, as long as you give appropriate credit to the original author(s) and the source, provide a link to the Creative Commons license, and indicate if changes were made. The images or other third party material in this article are included in the article's Creative Commons license, unless indicated otherwise in a credit line to the material. If material is not included in the article's Creative Commons license and your intended use is not permitted by statutory regulation or exceeds the permitted use, you will need to obtain permission directly from the copyright holder. To view a copy of this license, visit http://creativecommons.org/licenses/by/4.0/. 
pathways by $\mathrm{Bcl}-2$ inhibitors would make cancer cells under integrated stress more sensitive to death ${ }^{14}$. Proteasome inhibitors have been confirmed exerting a synergistic cytotoxicity when combined with Bcl-2 inhibitors ${ }^{15-17}$.

Previous works have reported the inhibitory effects of proton pump inhibitors (PPIs) on autophagy in low $\mathrm{pH}$ condition, which makes PPI transformed into the active molecule to inhibit the vacuolar-type $\mathrm{H}^{+}$-translocating ATPase (V-ATPase $)^{18-22}$. Moreover, Marino et al. ${ }^{19}$ reported that in addition to blocking the autophagic flux in low $\mathrm{pH}$ condition, ESOM also induced the early accumulation of autophagosomes.Thus we are wondering whether PPI has similar impacts on autophagy in neutral $\mathrm{pH}$ condition. Besides autophagy, the impact of PPI on another protein degradation system remains to be investigated because there was crosstalk between the ubiquitinproteasome and autophagy-lysosome systems. A dosedependent and time-dependent apoptotic-like cytotoxicity by PPI has been confirmed in B-cell lymphoma ${ }^{18}$, melanoma ${ }^{23}$, and multiple myeloma ${ }^{24}$. The effect of PPI was associated with alkalinization of lysosomal $\mathrm{pH}$ and lysosomal membrane permeabilization. Whether PPIinduced cell death was caspase dependent or not depended on tumor histology ${ }^{18,23,24}$, suggesting that the specificity of the death pathway depended on the original cell type. Moreover, the impacts of PPI on Bcl-2 family members have not been investigated, and whether they were involved in PPI-induced apoptosis remains to be seen. We focused on gastric cancer cell lines for the study because our previous works ${ }^{25,26}$ about pantoprazole were about gastric cancer. In this study, at least five unexplored mechanisms have been discovered and studied. First, PPI consistently promoted autophagosome formation in both low $\mathrm{pH}$ and neutral $\mathrm{pH}$ conditions, with TM9SF4-mTOR pathway playing an important role. Second, PPI-induced autophagy with increased SQSTM1 transcription, which was mediated by oxidative stress induced-Nrf2 in both low $\mathrm{pH}$ and neutral $\mathrm{pH}$ conditions. Third, pantoprazole inhibits proteasome function via transcriptionally reducing proteasome subunits partially via inhibiting STAT3 independent of $\mathrm{pH}$ conditions, which contributes to the activation of UPR and ER stress. Fourth, proteasome inhibition or ER stress was responsible for the activation of PPI-induced autophagy. Last but not least, Bcl-2/Bcl-xl inhibitors such as ABT-263 and ABT-737 have synergistic interaction with PPI in gastric cancer cells in both $\mathrm{pH} 7.4$ and $\mathrm{pH} 6.5$ conditions, which has a broad prospect in the field of cancer treatment.

\section{Results \\ PPI-induced autophagosome formation via TM9SF4-mTOR pathway}

The increased cytoplasmic vacuolation after PPI treatment was confirmed by transmission electron microscopy and GFP-LC3B puncta assay (Fig. 1a-c and Supplementary Figure S3a-c) in both low and neutral pH conditions. The transition from LC3B-I to LC3B-II was also enhanced in a dose-dependent manner and time-dependent manner (Fig. 1d-e and Supplementary Figure S3d), and real for different cancer cell lines (Supplementary Figure S1e). The key negative regulator of autophagy, mTOR signaling pathway and a number of autophagy regulators were significantly upregulated after PPI treatment (Fig. 1f, Supplementary Figure S2a and S2b, Supplementary Figure S3e and S3f $)^{27}$. To determine whether they were responsible for PPI-induced autophagy, we adopted genetic and pharmacological inhibition approaches. After Atg5 and Atg7 were knocked down by siRNA, the PPI-induced LC3B-II accumulation was abolished (Supplementary Figure S2c-f and Supplementary Figure S3g). On the contrary, disrupting class III PI3K complex, neither by knocking down Beclin 1 via siRNA or inhibiting PI3K using wortmannin (WM), there was no difference (Supplementary Figure S2c and S2g, Supplementary Figure S3g). Autophagy was an important adaptation mechanism for cancer cells when exposed to an acidic environment ${ }^{28}$. Cancer cells under microenvironmental stress (including low $\mathrm{pH}$ ) use to cannibalize other cells ${ }^{29}$. TM9SF4 has been recently reported as an important regulator of autophagy $^{30,31}$ and cannibalism ${ }^{29}$. Suppression of TM9SF4 by siRNAs attenuated the PPI-stimulated dephosphorylation of mTOR, RPS6, and 4E-BP1 (Fig. 1g, h). More important, knocking down TM9SF4 reduced LC3B accumulation after PPI treatment via reversed mTORC1 activity. In TCGA cohort, the mRNA expression level of TM9SF4 was also significantly correlated with important autophagy genes (Fig. 1i). Taken together, these data showed that PPI induced autophagosome formation via TM9SF4-mTOR pathway, consistent with recent studies ${ }^{30,32}$.

\section{PPI didn't always block the autophagic flux in neutral $\mathrm{pH}$}

Previous works ${ }^{18,19}$ have reported PPI as a V-ATPase inhibitor in low $\mathrm{pH}$ condition, with no apparent increase in LC3B and SQSTM1 accumulation after Baf A1 added (Supplementary Figure S4a), increased $\mathrm{GFP}^{+} \mathrm{RFP}^{+}$puncta (Supplementary Figure S4b) and reduced LysoTracker Red staining (LTR) (Supplementary Figure S4c). This could naturally explain for the accumulation of SQSTM1 after PPI treatment in low $\mathrm{pH}$ condition. However, in neutral $\mathrm{pH}$ condition, baf A1 dramatically caused further accumulation of LC3B-II by PPI, and PPI still increased the amount of LC3B-II in the presence of baf A1 (Fig. 2a). In line with the change of LC3B-II, dramatic increase in SQSTM1 was also observed (Fig. 2a). In PPI-treated cells, major parts of the LC3B-positive puncta were red, which showed the similar pattern as positive control torin 1 did (Fig. 2b). As shown in Fig. 2c, PPI resulted in a significant 


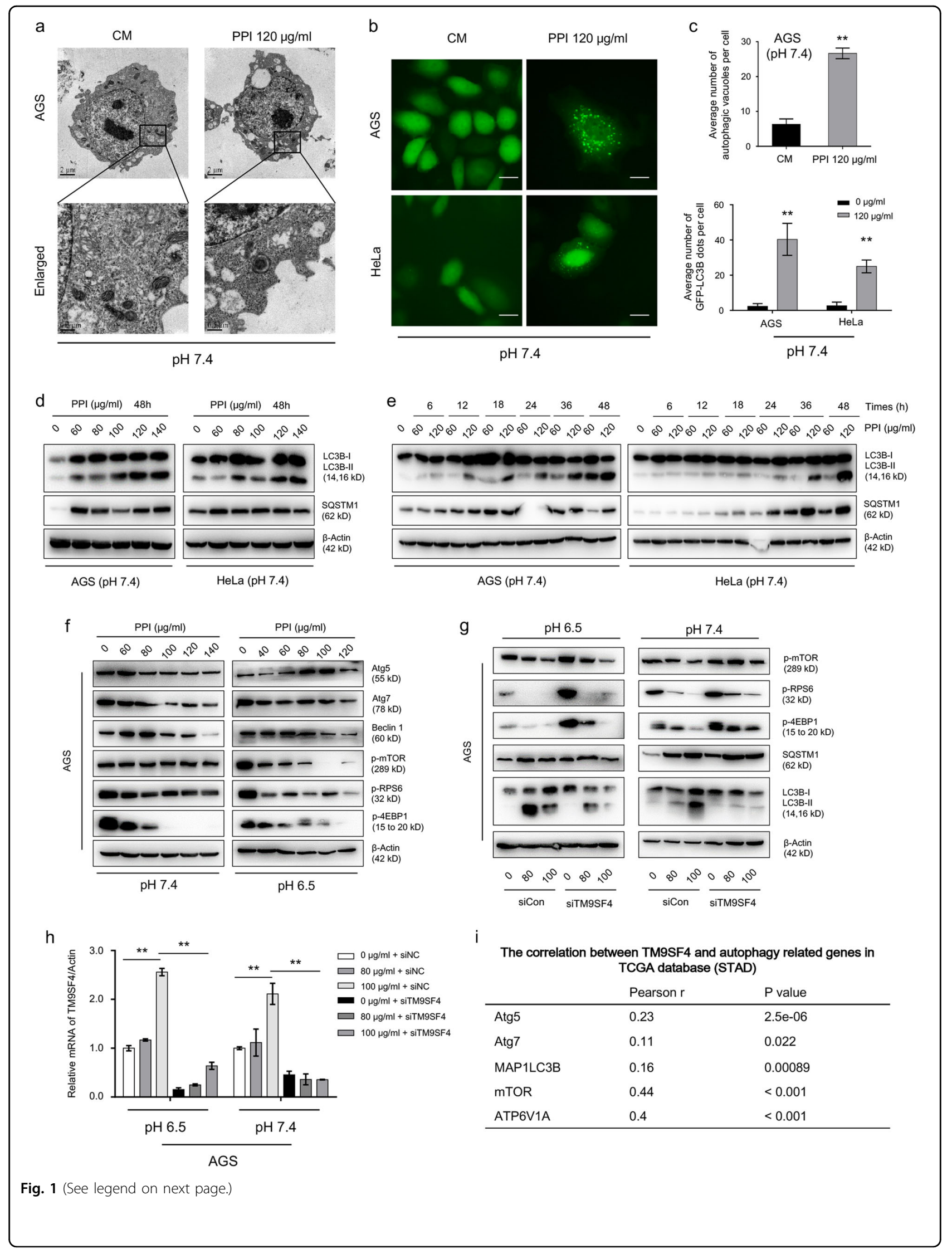


(see figure on previous page)

Fig. 1 Pantoprazole induced autophagosome biogenesis via TM9SF4-mTOR pathway. a AGS cells treated with $120 \mu \mathrm{g} / \mathrm{ml} \mathrm{PPI} \mathrm{for} 48 \mathrm{~h} \mathrm{in} \mathrm{pH} 7.4$ condition, were imaged by transmission electron microscopy. Representative micrographs showed increased abundance of lysosomes in cells after PPI treatment compared with control cells. Scale bar: $500 \mathrm{~nm}$. b AGS and HeLa cells transfected with GFP-LC3B plasmid were treated with $120 \mathrm{\mu g} / \mathrm{ml}$ PPI for $48 \mathrm{~h}$ in pH 7.4 condition. Scale bar: $20 \mu \mathrm{m}$. c The number of autophagic vacuoles and GFP-LC3B dots in each cell were quantified. Data were presented as mean \pm SD from three independent experiments $\left({ }^{* *} p<0.01\right.$, identified by Student's $t$-test). d, e AGS and HeLa cells were treated for $48 \mathrm{~h}$ in pH 7.4 condition with indicated concentrations of PPI, or treated with 60 and $120 \mu \mathrm{g} / \mathrm{ml} \mathrm{PPI}$ for the indicated times. Levels of LC3B-II and SQSTM1 protein were analyzed by western blot. $\beta$-actin served as an internal control. $\mathbf{f}$ mTOR pathway proteins levels in AGS cells after treated with PPI for 48 h both in pH 7.4 and 6.5 conditions, were detected by western blot analysis. $\mathbf{g}$, $\mathbf{h}$ AGS cells were transfected with TM9SF4 siRNA for 48 h, and then incubated with 80 and $100 \mu \mathrm{g} / \mathrm{ml}$ PPI for another $48 \mathrm{~h}$. The level of indicated proteins were analyzed by western blot (g). TM9SF4 knockdown efficiency was verified by Q-PCR (h). i Data showing the positive correlation between TM9SF4 and related autophagy genes mRNA expression in TCGA STAD corhort, were generated by GEPIA (http://gepia.cancer-pku.cn/detail.php?clicktag=correlation). Pearson's coefficient tests were performed to assess statistical significance

increase in acidic vesicles (LTR). In addition, the relatively predominant V-ATPase subunits exhibited an increase after PPI treatment (Fig. 2d and Supplementary Figure S4d-e), albeit to a different degree. Notably, the important regulators of lysosomal biogenesis such as TFE3 and TFEB, accompanied with key lysosomal enzymes, also showed an increased expression (Fig. 2e, Supplementary Figure S5d and S5e). These data indicated that PPI not only promoted autophagosome formation, but also induced lysosomal biogenesis. In order to examine whether the impact of PPI on V-ATPase was merely dependent on the $\mathrm{pH}$ condition ${ }^{18-20}$, more PPI-treated cancer cell lines had been screened based on LTR stainning in neutral $\mathrm{pH}^{33}$. Most of cell lines tested showed an increased LTR staining, with A549 exibiting the most increment (Fig. 2f and Supplementary Figure S5f), accompanied by increased V-ATPase subunits (Supplementary Figure S5g). However, MKN45 and U2OS showed reduced LTR staining. In MKN45 cells, the accumulation of SQSTM1 was not further increased after baf A1 added (Supplementary Figure S5h), supporting autophagic flux blockage. Unexpectedly, PPI-treated MKN45 cells still showed an increase in V-ATPase subunits (Supplementary Figure S5i), indicating that PPI decreased LTR staining not via reducing V-ATPase subunits, consistent with our findings about PPI in low $\mathrm{pH}$ condition. Most important, the PPI-induced SQSTM1 accumulation in neutral $\mathrm{pH}$ was sensitive to rapamycininduced autophagy in AGS cells, while resistent in MKN45 cells (Fig. 2g). Collectively, the impact of PPI on autophagic flux was mainly $\mathrm{pH}$ dependent, while regardless of the impact of PPI on LTR staining, PPI-induced lysosome biogenesis in parallel with autophagosome formation.

\section{The increased SQSTM1 by PPI was transcriptionally mediated by NFE2L2}

Since the accumulation of SQSTM1 by PPI was not always a result of autophagic flux blockage such as in neutral $\mathrm{pH}$ condition, then we measured the mRNA level of SQSTM ${ }^{8}$. PPI-induced SQSTM1 mRNA increase occurred both in low and neutral $\mathrm{pH}$ conditions, which indicated that this phenomenon was independent of acidic environment (Fig. 3a). Published data showed that SQSTM1 mRNA might be induced by ROS $^{34}$. Cancer cells generated ROS after PPI treatment for $48 \mathrm{~h}$ (Fig. 3b and Supplementary Figure S6a) in both conditions as previously reported ${ }^{18,19}$. To clarify the role of ROS in SQSTM1 mRNA increase, we first checked that preincubation with the ROS scavenger GSH $(4 \mathrm{mM})$ or NAC $(5 \mathrm{mM})$ diminished the ROS (data not shown), accompanied with a reversal of cell viability (CCK8), apoptotic phenotype (cleaved PARP) and integrated stress (p-p38) (Supplementary Figure S6b and S6c). PPI-induced SQSTM1 accumulation was significantly abrogated in the presence of NAC or GSH (Fig. 3c, d). Nrf2 is a transcription factor that could be activated in response to ROS. Remarkably, PPI induced Nrf2 expression (Fig. 3e and Supplementary Figure S6d) in both $\mathrm{pH}$ conditions, with its increased targets (Fig. 3e, f, Supplementary Figure S6d and S6e $)^{35}$. As there being antioxidant response elements (AREs) in the promoter regions of SQSTM $1^{36}$, Nrf2 could be responsible for increased SQSTM1 mRNA. In Nrf2 deficient cancer cells, the increased SQSTM1 protein and mRNA was reversed (Fig. 3g-i). However, there was no putative AREs in the promoter regions of $\mathrm{LC} \mathrm{B}^{36}$. Thus, we failed to detect any significant difference of LC3B-II by PPI between normal and Nrf2deficient cancer cells (Fig. 3g). The tight relationship between Nrf2 and SQSTM1 was not only tested in vitro, but also confirmed in gastric patients from online databases (TCGA, GSE63089, and GSE27342) (Supplementary Figure S6f). To summarize, these data suggested that Nrf2 activation increased SQSTM1 mRNA in both $\mathrm{pH}$ conditions, and contributed to the increased SQSTM1 protein level no matter whether PPI blocked the autophagic flux ( $\mathrm{pH}$ 6.5) or not ( $\mathrm{pH}$ 7.4), but was not associated with PPI-induced autophagy. 


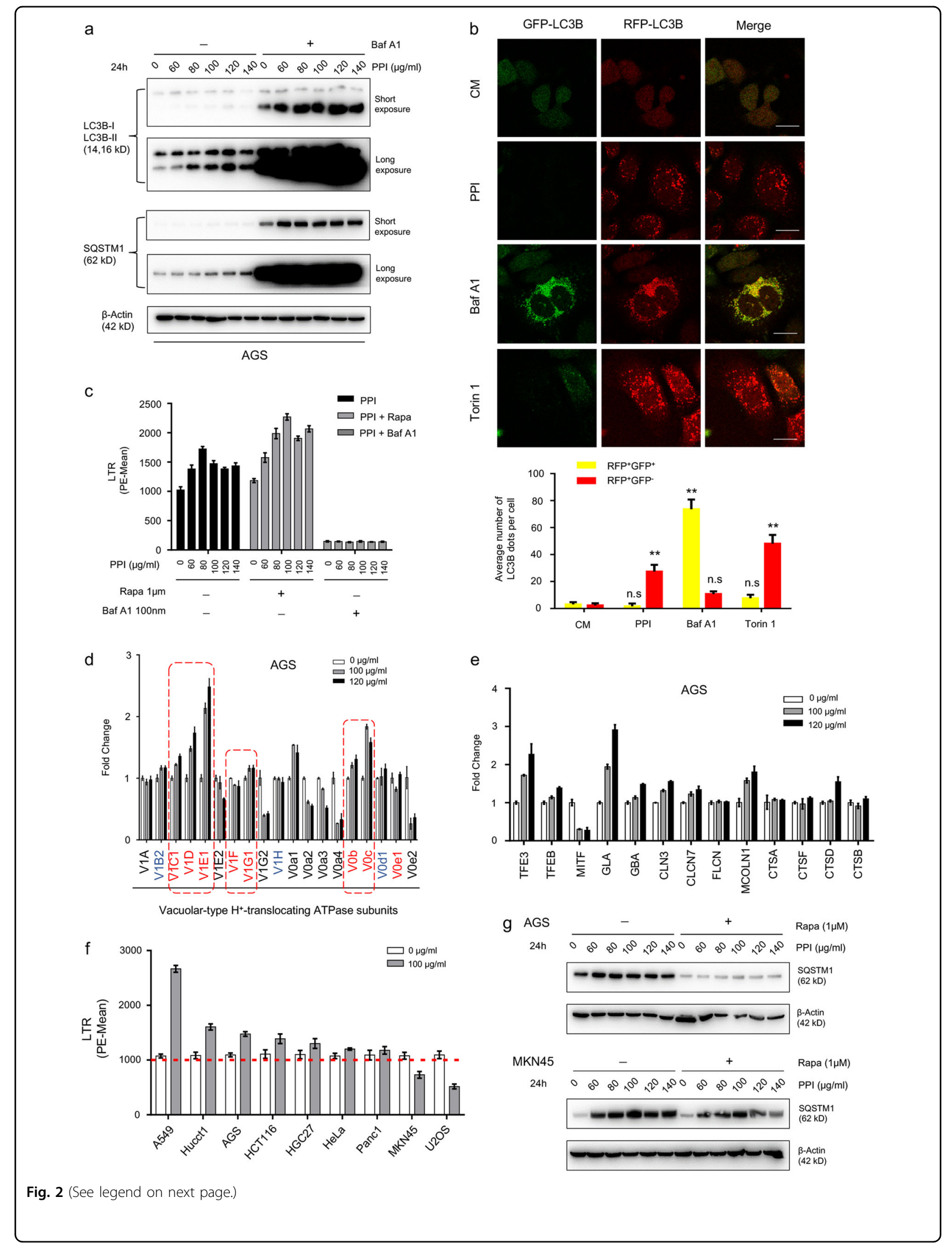




\begin{abstract}
(see figure on previous page)
Fig. 2 PPI didn't inhibit the fusion of autophagosomes and lysosomes in neutral pH condition. a AGS cells were either untreated or treated with PPI $(60-140 \mathrm{\mu g} / \mathrm{ml})$ for $24 \mathrm{~h}$ in $\mathrm{pH} 7.4$ condition in the absence or presence of classical autophagic flux inhibitor baf-A1 (100 nM). The indicated protein levels were analyzed by western blot. b AGS cells were transiently infected with GFP-mRFP-LC3B adenoviral particles for $48 \mathrm{~h}$ and subsequently treated with PPI $(120 \mathrm{\mu g} / \mathrm{ml})$, baf A1 $(100 \mathrm{nM})$, Torin $1(500 \mathrm{nM})$ for $48 \mathrm{~h}$ in pH 7.4 condition. The change of both green and red fluorescence was observed using a confocal microscope. Scale bar: $20 \mu \mathrm{m}$. Lower panel, the numbers of acidified autophagosomes (GFP ${ }^{-}$RFP ${ }^{+}$) versus neutral autophagosomes $\left(\mathrm{GFP}^{+} \mathrm{RFP}^{+}\right.$) per cell in each condition were quantified. Data were presented as mean $\pm \mathrm{SD}$ from three independent experiments (n.s. not significant; ${ }^{* *} p<0.01$, identified by two-way ANOVA with Dunnett's multiple comparison test). c AGS cells were either untreated or treated with PPI $(60-140 \mu \mathrm{g} / \mathrm{ml})$ for $24 \mathrm{~h}$ in $\mathrm{pH} 7.4$ condition in the absence or presence of rapamycin $(1 \mu \mathrm{M})$ or baf-A1 (100 nM), then stained with LysoTracker Red DND-99 dye (50 nM for $15 \mathrm{~min}$ ) for FACS analysis. Representative results of three independent experiments were shown. $\mathbf{d}$, e qRTPCR analysis of various V-ATPase subunits (d) and lysosomal genes (e) in AGS cells treated with $100 \mathrm{and} 120 \mathrm{\mu g} / \mathrm{ml} \mathrm{PPI} \mathrm{for} 48 \mathrm{~h} \mathrm{in} \mathrm{pH} 7.4 \mathrm{condition}$. Data were presented as mean \pm SD. f Different cancer cells were either untreated or treated with $100 \mathrm{\mu g} / \mathrm{ml} \mathrm{PPI}$ for $48 \mathrm{~h}$ in pH 7.4 condition, and then stained with LTR for FACS analysis. Representative results of three independent experiments were shown. $\mathbf{g}$ AGS and MKN45 cells were pretreated with indicated concentrations of PPI for $24 \mathrm{~h}$ in $\mathrm{pH} 7.4$ condition, and then incubated with or without rapamycin $(1 \mu \mathrm{M})$ for another $24 \mathrm{~h}$. The change pattern of SQSTM1 protein was determined by western blot
\end{abstract}

\section{Impaired proteasomal degradation also contributed to SQSTM1 accumulation}

It appeared that Nrf2-mediated transcriptional increase could fully explain SQSTM1 accumulation in neutral $\mathrm{pH}$ condition without impaired autophagic degradation ${ }^{8}$. However, to our surprise, in cancer cells overexpressing HA-tagged SQSTM1 plasmid without mRNA interference, PPI increased rather than decreased the levels of $\mathrm{HA}$ in neutral $\mathrm{pH}$ condition, while it was natural in low pH condition because PPI blocked autophagic flux (Fig. 4a and Supplementary Figure S7). Although SQSTM1 was a common substrate for autophagy, it was also degraded by proteasome and accumulated after proteasome inhibition $^{2-7}$. The SQSTM1 accumulation patterns due to autophagic flux blockage were confirmed (Fig. 4b, c), accompanied with undegraded LC3B-II. Corresponding to autophagy, when UPS inhibited, SQSTM1 also accumulated (Fig. 4d), with a further accumulation upon simultaneous inhibition of autophagy (Fig. 4e). Indeed, PPI treatment prolonged the half-life of exogenous SQSTM1 protein (HA) (Fig. 4f) in neutral $\mathrm{pH}$ condition, which indicated that PPI impaired the proteasomal degradation of SQSTM1. It is important to notice that, both in low and neutral $\mathrm{pH}$ conditions (Supplementary Figure S8), PPI treatment caused the colocalization of SQSTM1 with Ubiquitin, indicating that SQSTM1 was ubiquitylated, which was the characteristic of proteasome inhibition $^{37}$. More importantly, the accumulated SQSTM1 due to impaired UPS could still be cleared by autophagy (Fig. 4g), indicating no obstructed autophagic flux under proteasome inhibition. Similarly, accumulated SQSTM1 after PPI treatment could also be degraded via autophagy, while in low $\mathrm{pH}$ conditions the accumulated SQSTM1 couldn't be degraded via autophagy because of autophagic flux blockage (Fig. 4h). In order to rule out the interference of mRNA changes, we measured the SQSTM1 mRNA after PPI treatment with or without autophagy inducers. There was no elevated SQSTM1 mRNA reversing back after autophagy activation (Fig. 4i), showing that the decreased SQSTM1 protein level after autophagy activation was not due to reduced transcription. To summarize, the accumulated SQSTM1 was derived from not only increased transcription via Nrf2 but also reduced proteasomal degradation in both $\mathrm{pH}$ conditions.

\section{PPI inhibited proteasome function via reducing proteasome subunits expression}

According to the results above, we considered the UPS as a new potential target of PPI. First of all, polyubiquitinated proteins increased (Fig. 5a and Supplementary Figure S9a), suggesting that PPI inhibited proteasome function. TP53, the short-lived protein degraded by proteasome $\mathrm{e}^{2,6}$, accumulated after PPI treatment (Supplementary Figure S9b). Secondly, due to lacking the aromatic ketone structures ${ }^{38}$, PPI might inhibit the proteasome function on the transcriptional level. We noticed that PPI affected the mRNA of several proteasome and immunoproteasome subunits with a downward trend (Fig. 5b and Supplementary Figure S9c), which contributed to proteasome activity ${ }^{39,40}$. Prior work revealed a potential link between STAT3 and its transcriptional control of immunoproteasome subunits ${ }^{41}$. Along with the inhibited transcriptional activity of STAT3 (Supplementary Figure S10a) ${ }^{42}$, PPI reduced mRNA expression of PSMB8 and PSMB9 (Supplementary Figure S10b) in both pH conditions. We also confirmed the mRNA correlation between STAT3, PSMB8 and PSMB9 in online databases (Supplementary Figure S10c). However, the definite STAT3 binding sites were only confirmed in the promoter regions of PSMB8 and PSMB9 ${ }^{41}$, while PPI could make other proteasome subunits downregulated. As a result, PPI maybe reduce proteasome subunits expression via far more than just inhibiting STAT3. 


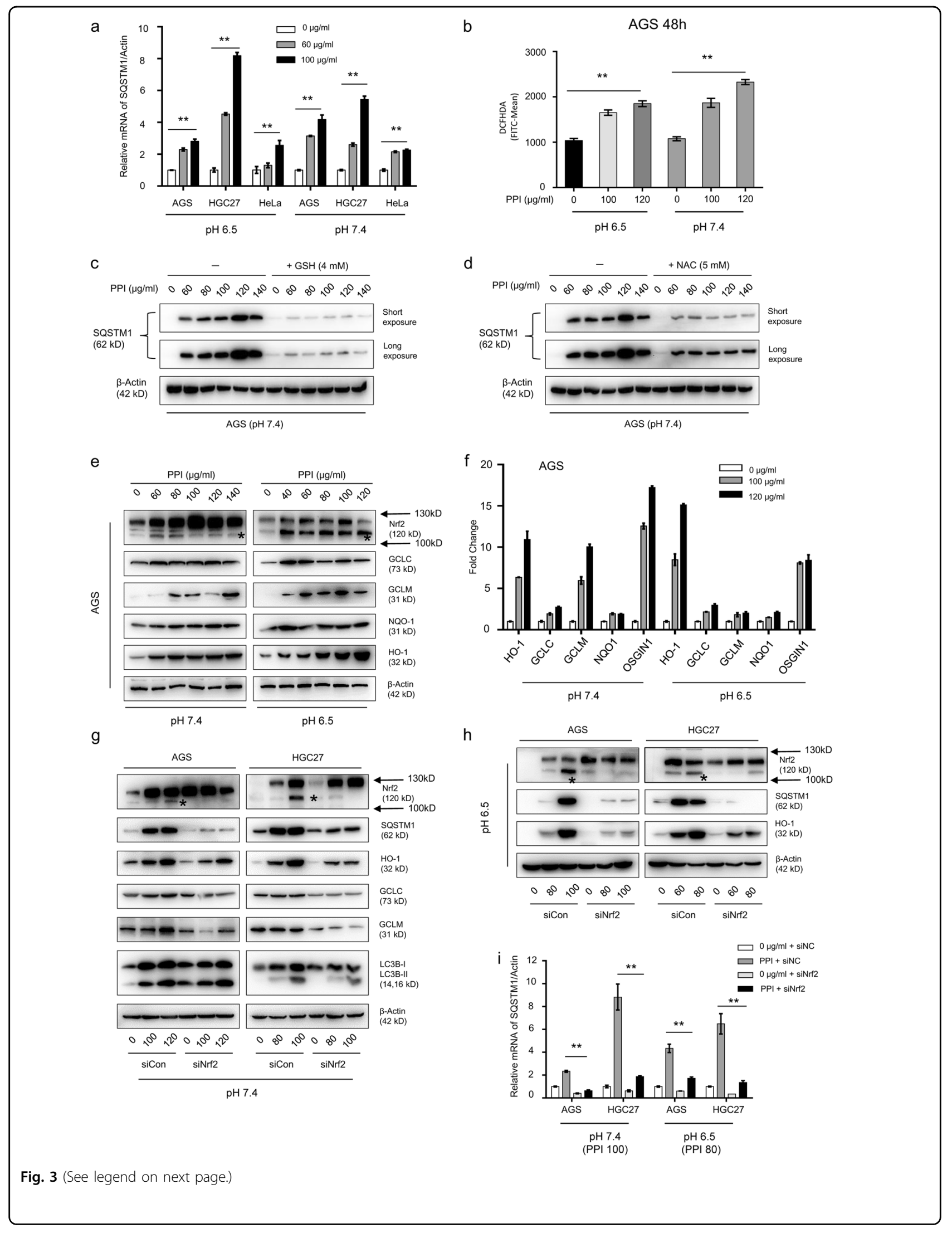




\begin{abstract}
(see figure on previous page)
Fig. 3 PPI upregulated SQSTM1 mRNA via NFE2L2. a AGS, HGC27, and HeLa cells were treated with 60 and $100 \mu \mathrm{g} / \mathrm{ml}$ PPI for $48 \mathrm{~h}$ in both pH 6.5 and pH 7.4 conditions, respectively. The SQSTM1 mRNA levels were assessed $*^{* *} p<0.01$, for each cell line using one-way ANOVA with Dunnett's multiple comparisons test). b AGS cells were treated with PPI for $48 \mathrm{~h}$ in both pH 6.5 and pH 7.4 conditions, and then stained with DCFHDA (5 $\mu \mathrm{M}$ ) for $30 \mathrm{~min}$. Intracellular ROS was reflected by the fluorescence intensity via flow cytometry analysis. Data presented were representative of three independent experiments ${ }^{* *} p<0.01$, identified by one-way ANOVA with Dunnett's multiple comparisons test). $\mathbf{c}, \mathbf{d}$ AGS cells were treated with PPI in the absence or presence of GSH ( $4 \mathrm{mM})$ (c) or NAC $(5 \mathrm{mM})$ (d) for $48 \mathrm{~h}$ in pH 7.4 condition. The expression level of SQSTM1 was measured by western blot. e, f AGS cells were exposed to various concentrations of PPI for $48 \mathrm{~h}$ in both pH 6.5 and pH 7.4 conditions. The levels of Nrf2 and its targets such as GCLC, GCLM, NQO1, and HO-1 were assessed by western blot analysis (e) and qRT-PCR analysis (f). Data were presented as mean \pm SD (** $p<0.01$, for each gene using one-way ANOVA Dunnett's multiple comparison test). $\mathbf{g}-\mathbf{i}$ AGS and HGC27 cells were reversely transfected with Nrf2 specific siRNA for $48 \mathrm{~h}$, and then exposed to indicated concentrations of PPI for $48 \mathrm{~h}$ in both pH 6.5 and pH 7.4 conditions. Knockdown efficiency of Nrf2 was confirmed by western blot analysis $(\mathbf{g}, \mathbf{h})$, and the change pattern of SQSTM1 was evaluated by both western blot $(\mathbf{g}, \mathbf{h})$ and qRT-PCR analysis (i). Data were presented as mean $\pm \mathrm{SD}\left({ }^{* *} p<0.01\right.$, identified by two-way ANOVA with Tukey's multiple comparisons test)
\end{abstract}

\section{ER stress/UPR was initiated upon proteasome inhibition by PPI}

An inactive proteasome made unfolded proteins accumulated in the ER, and then caused ER stress/UPR. We screened for ER stress related markers, with CHOP and peIF2a (Ser 52) showing a dose-dependent increase (Fig. 5c, d, Supplementary Figure S11a and S11b). ER Tracker staining and quantification by flow cytometry indicated ER expansion in PPI-treated cells (Fig. 5e, Supplementary Figure S11c $)^{43}$. In addition, perturbations in $\mathrm{Ca}^{2+}$ homeostasis upon ER stress were observed as early as for $24 \mathrm{~h}$ (Fig. 5f and Supplementary Figure S11d). The mRNA expression of SERCA (Sarco/ER $\mathrm{Ca}^{2+}$-ATPase for influx) and IP3R (inositol trisphosphate (IP3) receptor for efflux) was also examined, revealing a decrease in SERCA (the target of thapsigargin (TG)) and an increase in the most prominent isoform, ITPR3 (Supplementary Figure S11e and S11f). Protein overload in the ER induces autophagy $^{44,45}$. Both CHOP siRNA and the IP3Rs inhibitor 2$\mathrm{APB}$, could partially reverse the induction of LC3B-II by PPI (Fig. 5g, h) in both $\mathrm{pH}$ conditions, suggesting that ER stress after proteasome inhibition was located upstream of PPI-induced autophagy independent of $\mathrm{pH}$ conditions.

\section{PPI sensitized cancer cells to protein overload stress}

Sustained proteasome inhibition could lead to uncontrolled UPR and subsequent cell death. After pretreated with PPI for $24 \mathrm{~h}$, more AGS cells underwent apoptosis (Fig. 6a) when proteasome inhibition was aggravated by bortezomib or MG132, along with more polyubiquitinated proteins accumulated (Fig. 6b). Cell viability assay showed that, in the presence of bortezomib, PPI displayed a more profound cytotoxic effect, confirmed by Bliss index (1.53 \pm 0.148$)(\mathrm{pH} 7.4)$ (Fig. 6f) and Bliss index $(1.34 \pm 0.115)(\mathrm{pH} 6.5)$ (Supplementary Figure S12a). As a marker for protein overload stress ${ }^{43}$, the UPR genes also showed a further induction in combined approach. On the other side, preventing protein synthesis by cycloheximide $(\mathrm{CHX})$ could lessen PPI-induced UPR and apoptosis (Fig. 6c) and poly-ubiquitinated proteins accumulation (Fig. 6d). Reducing protein synthesis by mTOR inhibitor rapamycin or torin 1 also achieved similar results (Fig. 6e). In cells with low levels of protein synthesis, the cytotoxic effect of PPI decreased, with both Bliss indexs (pH 7.4: CHX: $0.30 \pm 0.09$; Torin 1: $0.81 \pm$ 0.03. pH 6.5: CHX: $0.75 \pm 0.15$; Torin 1: $0.77 \pm 0.08$ ) lower than 1, and the increased UPR genes reverting to normal levels (Fig. 6g, h, and Supplementary Figure S12b and S12c).

Autophagy is often activated as an important compensatory response for proteasome inhibitors ${ }^{4-6,46}$. Further inhibiting proteasome by bortezomib promoted PPIinduced autophagy (Supplementary Figure S13a and $\mathrm{S} 13 \mathrm{~b})$. On the contrary, when protein synthesis was aborgated or suppressed, the induced autophagy by PPI was reverted (Supplementary Figure S13c-f). Simultaneous inhibition of autophagy upon bortezomib treatment caused further accumulation of ubiquitinated proteins, and made cells more prone to apoptosis (Supplementary Figure S14a and S14b). Similarly, when the early stage of autophagy was genetically inhibited, PPI also made more cancer cells undergo apoptosis (Supplementary Figure S14c), even though the degree of increase varied in cell lines. When autophagic flux was inhibited, consistent results were achieved (Supplementary Figure S14d and S14e). Given the fact that PPI blocked autophagic flux in low $\mathrm{pH}$ condition, there was an interesting comparison showing that, the same amount of PPI caused more protein overload stress and UPR markers in pH 6.5 than $\mathrm{pH}$ 7.4, which was quantified by ER Tracker staining (Supplementary Figure S14f) and Q-PCR (Supplementary Figure S14g). Similar results were also achieved by adding HCQ into the PPI-treated cancer cells in $\mathrm{pH} \mathrm{7.4,} \mathrm{which}$ indicating that the increased protein overload stress in $\mathrm{pH}$ 6.5 was due to autophagy inhibition.

These observations suggested that, based on the proteasome inhibitory effect of PPI, both proteasome and autophagy inhibitors would have a synergistic interaction with PPI, and PPI sensitized cancer cells to death under protein overload stress. 


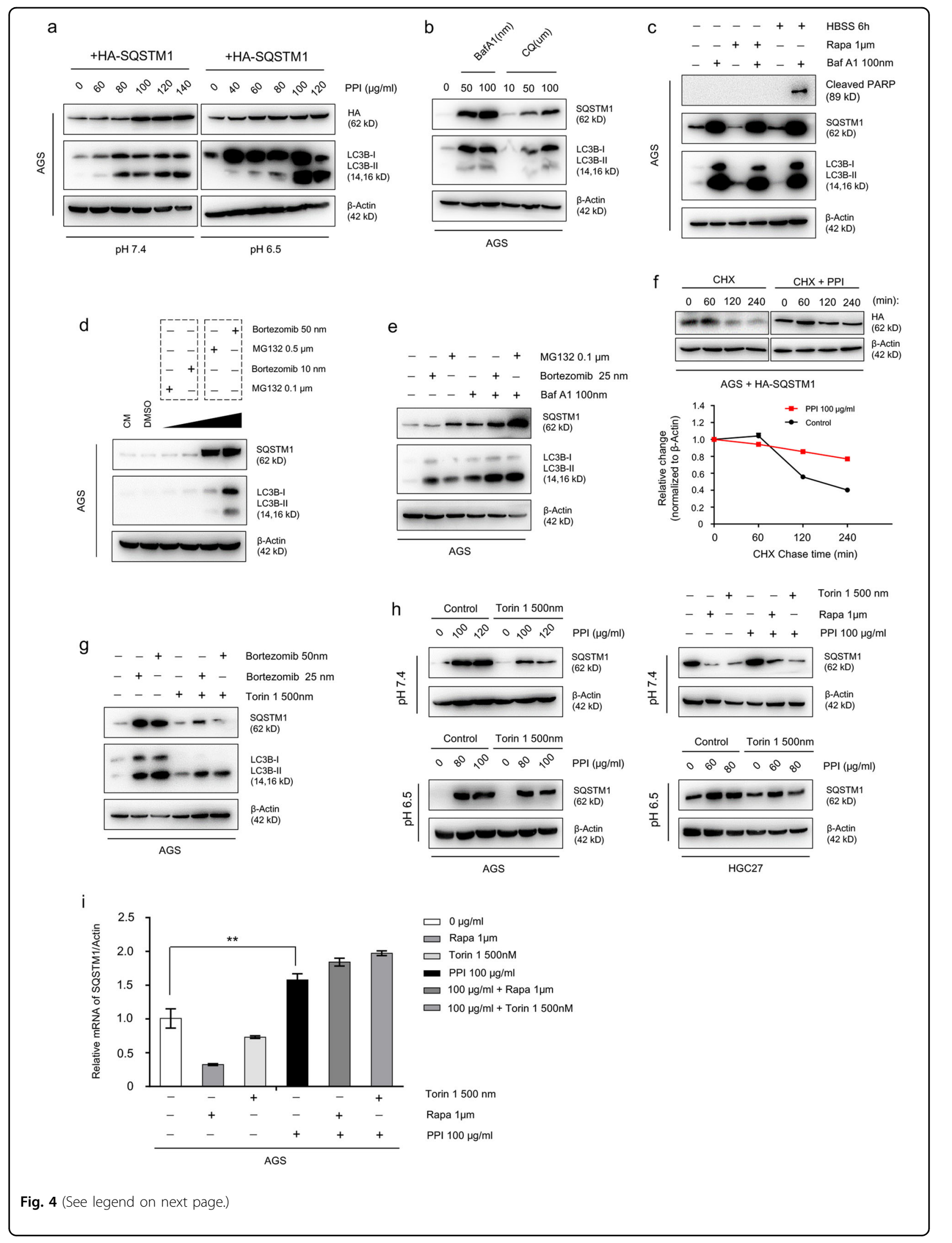


(see figure on previous page)

Fig. 4 PPI-induced accumulation of exogenous SQSTM1 via ubiquitin-proteasome pathway. a AGS cells were transfected with HA-tagged SQSTM1 plasmid for $48 \mathrm{~h}$, and then treated with PPI for another $48 \mathrm{~h}$ in both pH 6.5 and pH 7.4 conditions. The exogenous SQSTM1 protein was detected with antibody for HA. b AGS cells were treated with baf A1 (50 and $100 \mathrm{nM}$ ) and HCQ (10, 50, and $100 \mu \mathrm{M})$ for $24 \mathrm{~h}$. c AGS cells were pretreated with baf A1 (100 nM) for $30 \mathrm{~min}$, followed with $1 \mu \mathrm{M}$ rapamycin or amino acid starvation by HBSS for another $24 \mathrm{~h}$. d Different concentrations of two classical proteasome inhibitors Bortezomib and MG132 were added. e AGS cells were either untreated or treated with Bortezomib $(25 \mathrm{nM})$ or MG132 $(0.1 \mu \mathrm{M})$ for $24 \mathrm{~h}$ in the absence or presence of baf A1 (100 nM). f AGS cells transfected with HA-tagged SQSTM1 plasmid, were treated with $25 \mu \mathrm{g} / \mathrm{ml}$ cycloheximide (CHX) over a 240-min time period (left) or treated with $100 \mu \mathrm{g} / \mathrm{ml} \mathrm{PPI} \mathrm{for} 48 \mathrm{~h}$ in $\mathrm{pH} 7.4$ conditions, and then followed by $25 \mathrm{\mu g} / \mathrm{ml} \mathrm{CHX}$ over a 240-min time period (right). Cells were lysed at the indicated time points (0,60, 120, and 240 min). Right panel showed the half-life of HA, which reflected the stability of exogenous SQSTM1 protein. $\mathbf{g}-\mathbf{i}$ The accumulated SQSTM1 by either proteasome inhibitors or PPI was sensitive to autophagy mediated degradation. AGS cells were pretreated with 25 and $50 \mathrm{nM}$ bortezomib for $1 \mathrm{~h}$, and then incubated with $500 \mathrm{nM}$ torin 1 for $24 \mathrm{~h}(\mathbf{g})$. After pretreatment with PPI for $24 \mathrm{~h}$ in pH 7.4 or pH 6.5 condition, rapamycin $(1 \mu \mathrm{M})$ or torin 1 $(500 \mathrm{nM})$ was added for another $24 \mathrm{~h}(\mathbf{h})$. The protein level of SQSTM1 was measured by western blot analysis $(\mathbf{g}, \mathbf{h})$, and the change pattern of SQSTM1 mRNA was confirmed by qRT-PCR (i) ${ }^{* *} p<0.01$, identified by one-way ANOVA with Dunnett's multiple comparison test)

\section{The Bcl-2 inhibitors synergized the cytotoxicity of PPI}

Similar to previous results ${ }^{18,23,24}$, in gastric cancer cells, caspase activation is involved in PPI-induced cell death, but caspase inhibition could only partially reduce PPIinduced cell death in both conditions (data not shown). Taking into account the increased mROS (Supplementary Figure S15a) and influx of calcium into mitochondria (Supplementary Figure S15b) after PPI treatment, cotargeting mitochondria together with PPI may represent a new platform to sensitize cancer cells to death. Apoptosis was guarded by Bcl-2 family proteins ${ }^{12}$. We found the interesting trend of antiapoptotic proteins increasing and proapoptotic proteins decreasing (Fig. 7a, b), which may limit the pro-cell death effect of PPI. We pretreated PPI for $24 \mathrm{~h}$ and then added ABT-263/737 for another $24 \mathrm{~h}$. This combination therapy produced a significantly advantage over each drug alone (Fig. 7c, Supplementary Figure S15c, Supplementary Figure S16a and S16c). Formal synergy analyses were performed, and the synergistic cell viability inhibitory effect was observed (Fig. 7c, d, Supplementary Figure S15c and S15d, Supplementary Figure S16c and S16d). The increased cell death was also confirmed (Supplementary Figure S15e and S15f), and the combination strategy almost totally induced mitochondrial membrane depolarization (Fig. 7e and Supplementary Figure S15f). Correspondly, more damage was brought to mitochondria (Fig. $7 \mathrm{f})^{47}$. The synergistic cytotoxicity of combination therapy was also indicated by increased apoptosis with elevated cleaved PARP and cleaved caspase 3 , accompanied with more cytochrome c releasing into cytoplasm (Fig. $7 \mathrm{~g}$ ). These data provided support that, cotargeting induced antiapoptotic Bcl-2 proteins by PPI, was an important complementary strategy for strengthening the cytotoxicity of PPI, both in low $\mathrm{pH}$ and neutral $\mathrm{pH}$ conditions.

\section{Discussion}

Previous works have shown that the accumulation of LC3B and SQSTM1 by PPI in low $\mathrm{pH}$ condition, was associated with the inhibitory effect of PPI on V-ATPase. However, according to our work, in neural $\mathrm{pH}$ condition where PPI was unable to inhibit V-ATPase, PPI could still cause LC3B and SQSTM1 accumulation. These results showed that the impacts of PPI on autophagy were not merely the autophagic flux blockage in low $\mathrm{pH}$ condition $^{19}$. Recent studies also found that TM9SF4 could regulate autophagy initiation in response to nutrient starvation by inhibiting the nutrient-sensing kinase complex mTORC $1^{30}$. Indeed, we found that PPI markedly reduced the mTOR activity consistent with previous reports ${ }^{25}$, as indicated by dephosphorylation of mTOR, 4E-BP1 and RPS6. Intriguingly, TM9SF4-siRNAs substantially attenuated the PPI-induced mTOR inactivation, and more important LC3B accumulation. These data provide strong evidence that TM9SF4 acts through mTOR to facilitate autophagosomes formation induced by PPI in different $\mathrm{pH}$ conditions.

SQSTM1 accumulation in neutral $\mathrm{pH}$ condition after PPI treatment without V-ATPase inhibition also made the actual sources of increased SQSTM1 confusing 9 . Consistent with the increased SQSTM1 mRNA in esomeprazole-treated EAC cells ${ }^{22}$, PPI elevated SQSTM1 mRNA via Nrf2 in both $\mathrm{pH}$ conditions dependent on ROS generation $^{35,36}$. Our inertial thinking usually assumed SQSTM1 accumulation to be totally mediated by Nrf2 especially in neutral $\mathrm{pH}$ condition, but the accumulation of exogenously expressed SQSTM1 made us aware of the potential decreased protein degradation by other system, such as UPS. In our hands, PPI inhibited proteasome function via reducing various proteasome subunits expression, even though the responsible transcription factors besides STAT3 must be elucidated in future. The colocalization of SQSTM1 with Ub indicated that, proteasome function was inhibited after PPI treatment, and then SQSTM1 was ubiquitylated and mediated the transient aggregation of ubiquitinated proteins, such as proteasome, aggresome, and ALIS formation to regulate the proteostasis ${ }^{7}$. The specific progress mediated and 


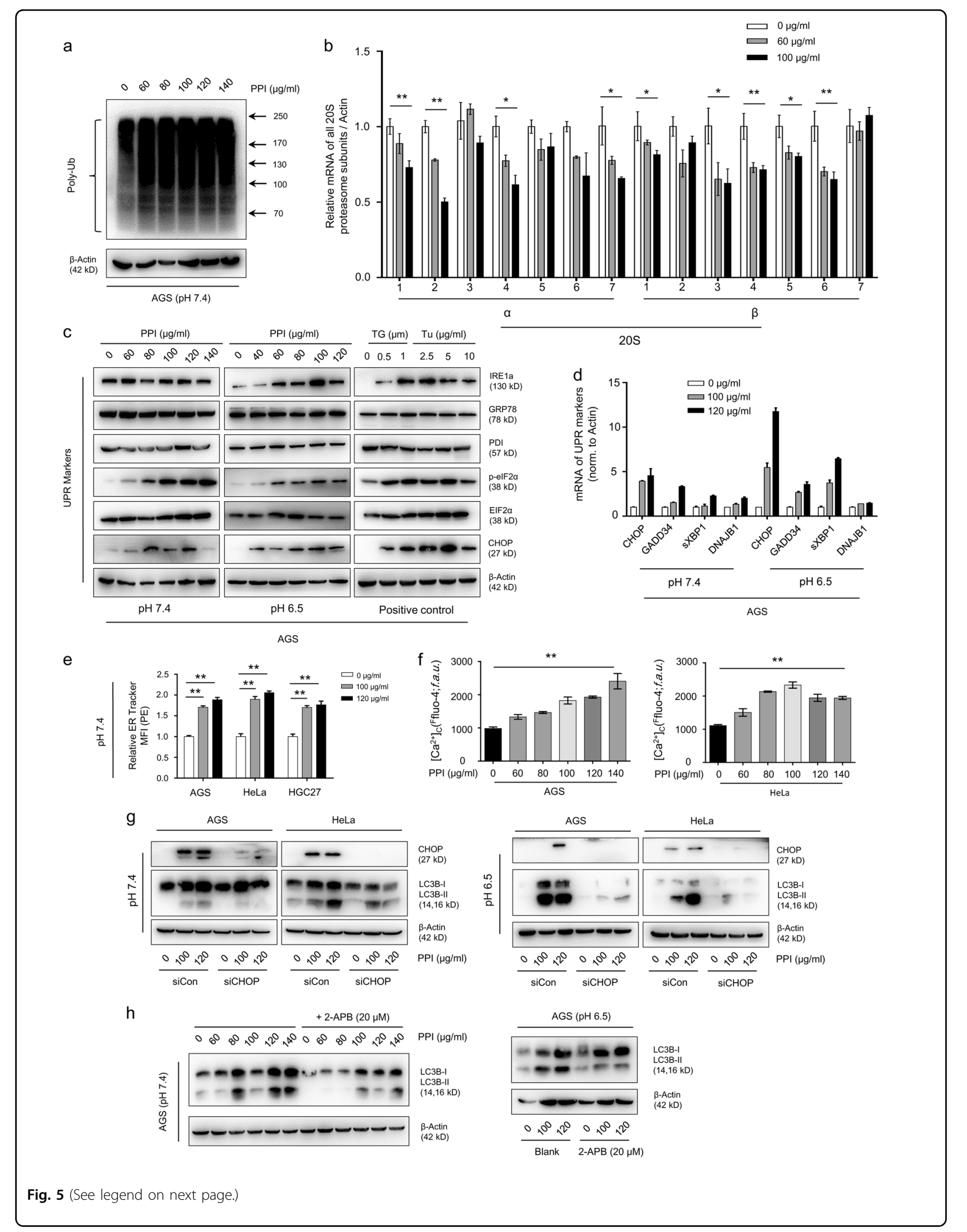


(see figure on previous page)

Fig. 5 PPI reduced proteasome expression and induced ER stress in cancer cells. a AGS cells were treated with indicated concentrations of PPI for $48 \mathrm{~h}$ in pH 7.4 condition, followed by measuring proteasome function via western blot analysis using specific antibody to ubiquitin. $\mathbf{b}$ The mRNA expression level of the $20 \mathrm{~S}$ proteasome subunits were measured after PPI treatment for $48 \mathrm{~h}$ in $\mathrm{pH} 7.4$ condition. Data were presented as mean \pm SD $\left({ }^{*} p<0.05,{ }^{* *} p<0.01\right.$, for each gene using one-way ANOVA with Dunnett's multiple comparisons test). c Western blot analysis of ER stress-related proteins after PPI treatment for $48 \mathrm{~h}$ in both pH 7.4 and pH 6.5 conditions. Cells treated with Thapsigargin (TG, 0.5 and $1 \mu \mathrm{M})$ or Tunicamycin (Tu, 2.5, 5 and $10 \mu \mathrm{g} / \mathrm{ml}$ ) for $24 \mathrm{~h}$ served as positive controls. d qRT-PCR analysis of UPR genes after $48 \mathrm{~h}$ of PPI (100 and $120 \mu \mathrm{g} / \mathrm{ml})$ treatment in both pH 7.4 and $\mathrm{pH} 6.5$ conditions. Data were presented as mean $\pm \mathrm{SD}\left({ }^{* *} p<0.01\right.$, for each gene using one-way ANOVA with Dunnett's multiple comparisons test). e ER-Tracker Red (500 nM) staining of PPI treated cells in $\mathrm{pH} 7.4$ condition was performed. The quantification of ER Tracker fluorescence were accomplished by FACS. Data presented were representative of three independent experiments $\left({ }^{* *} p<0.01\right.$, for each cell line using one-way ANOVA with Dunnett's multiple comparisons test). f After treated with PPI $(60-140 \mu \mathrm{g} / \mathrm{ml})$ for $24 \mathrm{~h}$ in pH 7.4 condition, cells were then incubated with $5 \mu \mathrm{M}$ Fluo-4/AM and detected by flow cytometry. Data presented were representative of three independent experiments ${ }^{* *} p<0.01$, identified by one-way ANOVA with Dunnett's multiple comparisons test). $\mathbf{g}$, $\mathbf{h}$ PPI-induced ER stress contributed to the acitivation of autophagy. AGS and HeLa cells transfected with CHOP-specific siRNA, were treated with 100 and $120 \mu \mathrm{g} / \mathrm{ml} \mathrm{PPI} \mathrm{for} 24 \mathrm{~h}$ in both pH 7.4 and pH 6.5 conditions (g). AGS cells were treated with the indicated concentrations of PPI in the absence or presence of 2-APB (20 $\mu \mathrm{M})$ for $24 \mathrm{~h}$ in both pH 7.4 and pH 6.5 conditions (h). The autophagy marker LC3B-II was determined

structure formed by SQSTM1 after PPI treatment needs further investigations.

Proteostasis is a key requirement for cancer cell viability and stress adaptation, with protein degradation systems maintaining the balance ${ }^{2}$. Our results indicated that heightened protein synthesis was a prominent source of ER stress/UPR in PPI treated cancer cells. Further inhibiting proteasome function with bortezomib augmented the PPI-induced UPR, and triggered synergistic cytotoxicity compared with either drug alone. Autophagy was activated to counterbalance ER expansion during $\mathrm{UPR}^{44,45}$. Indeed, we found that knockdown $\mathrm{CHOP}$ or inhibiting ER $\mathrm{Ca}^{2+}$ efflux by 2-APB markedly reduced the accumulation of LC3B. Since autophagy plays a role in loosening protein overload stress, cotargeting autophagy may be a promising approach for amplifying the tumor killing effects of proteasome inhibitors ${ }^{48-50}$. Notably, in our hands, autophagy inhibition with HCQ or Atg5/Atg7 RNAi sensitized cancer cells to PPI-induced cell death. Moreover, compared with the cells in neutral $\mathrm{pH}$ condition, cells in low $\mathrm{pH}$ condition showed more protein overload stress, accompanied with increased apoptosis (data not shown). These results presented herein are in keeping with previous reports supporting a protective role of PPI-induced autophagy ${ }^{19}$. To summarize, PPI treatment could sensitize cancer cells to death under protein overload stress either by proteasome inhibition or autophagy deficiency, and the combination strategies of PPI with both proteasome inhibitors and autophagic flux blockers would be promising approaches for cancer treatment (Fig. 8).

Bcl-2 inhibitors targeting against antiapoptotic family members offer the prospect of silencing prosurvival pathways ${ }^{12}$, and lower the threshold required to initialize apoptosis. Considering for the induced antiapoptotic proteins after PPI treatment, the cytotoxicity of PPI significantly increased when combined with $\mathrm{Bcl}-2$ inhibitors.
The pro-cell death effect of PPI was correlated with, or may be partially governed by, the proximity of cancer cell mitochondria to the apoptotic threshold, which could be shortened by Bcl-2 inhibitors. Future studies that characterize the specific pathways mediating synthetic lethality following PPI and Bcl-2 inhibitors may provide additional strategies to enhance cancer cell death.

\section{Materials and methods \\ Cell culture}

The human cancer cell lines including AGS, HGC27, HeLa, Panc-1, HCT116, A549, and U2OS were purchased from the Cell Resource Center, Institute of Biochemistry and Cell Biology, Shanghai Institutes for Biological Sciences, Chinese Academy of Sciences (Shanghai, China). MKN45 was purchased from the Cell Resource Center, Institute of Basic Medical Sciences, Chinese Academy of Medical Sciences (Beijing, China). Hucct1 were obtained from the Japanese Collection of Research Bioresources (JCRB) (Tokyo, Japan). The cell lines were originally authenticated in China Center for Type Culture Collection (CCTCC) by Short Tandem Repeat (STR) profiling and passaged less than 6 months in the lab. These cells are routinely maintained in the laboratory of our group.The acid cell culture medium ( $\mathrm{pH}$ 6.5) was obtained by the addition of $1 \mathrm{M} \mathrm{HCl}$ solution as previously reported ${ }^{23,24}$. The $\mathrm{pH}$ was estimated by the use of a FE20 FiveEasy Plus $\mathrm{pH}$ Meter (METTLER TOLEDO Instruments (China), Shanghai, China).

\section{Cell viability assay and quantitative methods for drug interaction analysis}

Different cancer cells (5000 cells per well) were seeded into 96-well plates and then allowed for adherence and culture overnight at $37^{\circ} \mathrm{C}$. PPI was dissolved in complete medium $(\mathrm{CM})$, and other different reagents were dissolved in optimal solvent such as DMSO, whose final 


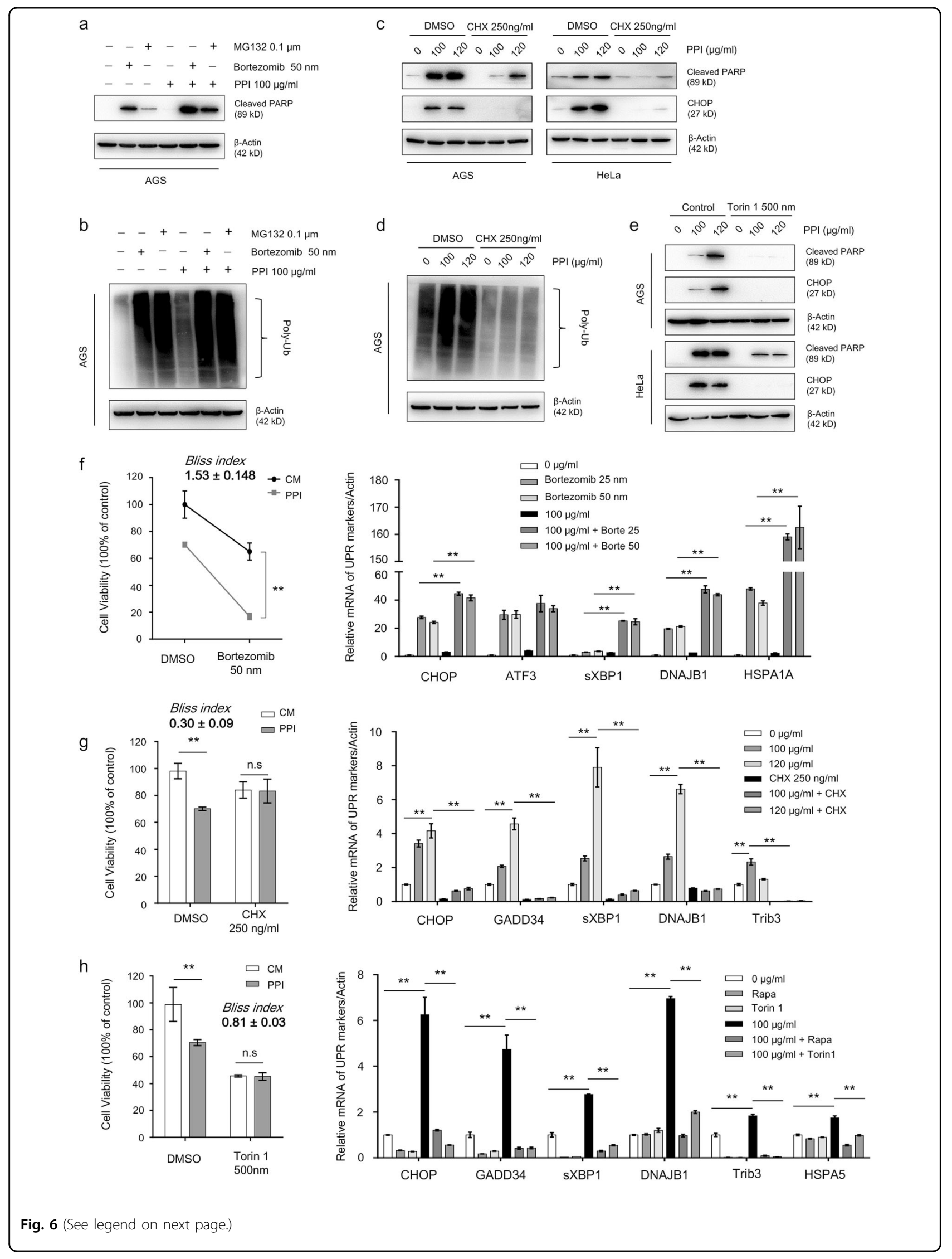


(see figure on previous page)

Fig. 6 Proteasome inhibitors aggravated while protein synthesis suppression ameliorated the UPR and cell death by PPI. a, b AGS cells were pretreated with PPI $(100 \mu \mathrm{g} / \mathrm{ml})$ for $24 \mathrm{~h}$ in $\mathrm{pH} 7.4$ condition, followed by combination with or without $50 \mathrm{nM}$ Bortezomib or $0.1 \mu \mathrm{M}$ MG132 for another $24 \mathrm{~h}$. Western blot analysis of apoptosis related protein cleaved-PARP levels (a) and poly-ubiquitinated proteins (b). c, d AGS and HeLa cells were pretreated with $\mathrm{CHX}(250 \mathrm{ng} / \mathrm{ml})$ for $2 \mathrm{~h}$, and then incubated with PPI $(100 \mu \mathrm{g} / \mathrm{ml}$ or $120 \mu \mathrm{g} / \mathrm{ml})$ for $48 \mathrm{~h}$ in pH 7.4 condition. Levels of apoptosis related protein cleaved-PARP, UPR marker CHOP (c), and poly-ubiquitinated proteins (d) were analyzed. e AGS and HeLa cells were pretreated with torin $1(500 \mathrm{nM})$ for $2 \mathrm{~h}$, and then incubated with PPI $(100 \mu \mathrm{g} / \mathrm{ml}$ or $120 \mu \mathrm{g} / \mathrm{ml})$ for $48 \mathrm{~h}$ in pH 7.4 condition. Indicated proteins were analyzed by western blot. $\mathbf{f}$ AGS cells were treated as described in (a). The cell viability was determined by CCK8 assay (left) $\left({ }^{* *} p<0.01\right.$, identified by two-way ANOVA with Sidak's multiple comparisons test). qRT-PCR analysis of UPR genes was performed (right) $\left(^{* *} p<0.01\right.$, for each gene using one-way ANOVA with Tukey's multiple comparisons test). g AGS cells were treated as described in (c). The cell viability was determined by CCK8 assay (left) (** $p<0.01$, identified by two-way ANOVA with Sidak's multiple comparisons test). qRT-PCR analysis of UPR genes was performed (right) (** $p<0.01$, for each gene using one-way ANOVA with Tukey's multiple comparisons test). $\mathbf{h}$ AGS cells were treated as described in (e). The cell viability was determined by CCK8 assay (left) ${ }^{* *} p<0.01$, identified by two-way ANOVA with Sidak's multiple comparisons test). qRT-PCR analysis of UPR genes was performed (right) $\left(^{* *} p<0.01\right.$, for each gene using one-way ANOVA with Tukey's multiple comparisons test)

concentration was guaranteed to be less than $1 \%$. The order in which the drugs were added, and the time of sustained exposure, were described in detail in the section of Results and Figure legends. Hundred microliter CCK-8 working solutions were added into each well of 96-well plates after treatment, and plates were incubated at $37^{\circ} \mathrm{C}$ for another $1-1.5 \mathrm{~h}$. The absorbance at $450 \mathrm{~nm}$ was measured, and the percentage of cell viability or cell viability inhibition was calculated by using the absorbance values of untreated control cells $(\mathrm{C})$, and drug-treated cells $(\mathrm{T})$ as follows: $\mathrm{T} / \mathrm{C} \times 100$ for cell viability, where untreated cells set as $100 \%$, and $(\mathrm{C}-\mathrm{T}) / \mathrm{C} \times 100$ for cell viability inhibition, where untreated cells set as $0 \%$. All experiments were carried out in quintuplicate for technical repetition, and performed in triplicate for biologic repetition.

To assess the synthetical effect of pantoprazole with other drugs, we adopted two methods for determining the drug interaction under different circumstances. One is to calculate the ratio of observed $[\operatorname{Eobs}(x, y)]$ and expected $[\operatorname{Eexp}(x, y)]$ responses according to the Bliss method ${ }^{51}$. The formula for predicting expected effect is as follows: $\operatorname{Eexp}(x, y)=E x+E y-\left(E x^{*} E y\right)$, where Ex and Ey are each separate drug effect. It should be noted that the Bliss index of $1,<1$ or $>1$ indicates additive, antagonistic or synergistic effects, respectively. CI is an another quantitative measure for determing the degree of drug interaction with synergism $(\mathrm{CI}<1)$, additive effect $(\mathrm{CI}=1)$, or antagonism $(\mathrm{CI}>1)$ for a given final measurement, which is different from the Bliss index ${ }^{52}$. CIs were calculated by using CalcuSyn software program (BIOSOFT, Cambridge, UK).

\section{Reagents and drugs}

Pantoprazole sodium in powder (PANTOLOC) was purchased from Takeda GmbH (Germany). Bafilomycin A1 (Baf-A1, S1413), Hydroxychloroquine Sulfate (HCQ, S4430), Rapamycin (Rapa, S1039), Wortmannin (WM, S2758), and Nutlin-3a (S8059), were purchased from
Selleck Chemicals (Houston, TX, USA). N-acetyl-Lcysteine (NAC, A7250), 2',7'-Dichlorofluorescin diacetate (DCFHDA, D6883), L-Glutathione reduced (GSH, G4251), Thapsigargin (TG, T9033), and 2-Aminoethyl diphenylborinate (2-APB, D9754) were purchased from Sigma-Aldrich (St. Louis, MO, USA). Torin 1 (HY-13003), Tunicamycin (Tu, HY-A0098), Cycloheximide (CHX, HY-12320), Bortezomib (borte, HY-10227), and MG-132 (HY-13259) were purchased from MedChem Express (Shanghai, China). LysoTracker Red DND-99 (L7528), and Fluo-4,AM (F23917), Rhod-2,AM (R1245MP), MitoSOX $^{\mathrm{mm}}$ Red (M36008), MitoTracker ${ }^{\mathrm{Tm}}$ Green (M7514), MitoTracker $^{\text {ma }}$ Red CMXRos (M7512), and JC-1 Mitochondrial Membrane Potential Dye (T3168) were purchased from Molecular Probes (USA). ABT-263 (Navitoclax) (A3007) and ABT-737 (A8193) were purchased from Apex Bio (Houston, TX, USA). Lipofectamine 3000 (L3000008) and Lipofectamine RNAiMAX (13778150) were purchased from Invitrogen.

\section{Plasmids, siRNAs and transfections}

The pBABE-puro-EGFP-LC3 was purchased from Addgene (22405, deposited by Jayanta Debnath (University of California, San Francisco, CA, USA)). Fulllength HA-tagged SQSTM1 and HA-tagged Ubiquitin plasmids were kind gifts from Dr. Mingming Zhang (Nanjing, China). For plasmids transfection, AGS and HeLa cells were seeded into 6-well plates at a density of $20-25 \times 10^{4}$ cells/well for overnight and transiently transfected using Lipofectamine 3000 according to the manufacturer's instructions. The siRNA oligonucleotides targeting Atg5, Atg7, Beclin 1, Nrf2, CHOP, and negative control siRNA were all chemically synthesized by RiboBio (Guangzhou, China) and resuspended in RNase-free water to a stock concentration of $20 \mu \mathrm{M}$. The siRNA sequences were detailed in Supplementary Table 1. AGS, HGC27, and HeLa cells were reversely transfected as follows: $5 \mu \mathrm{l}$ of $20 \mu \mathrm{M}$ siRNA and $5 \mu \mathrm{l}$ Lipofectamine RNAiMAX were mixed with $400 \mu \mathrm{l}$ of Opti-MEM (Gibco) in sterilized 


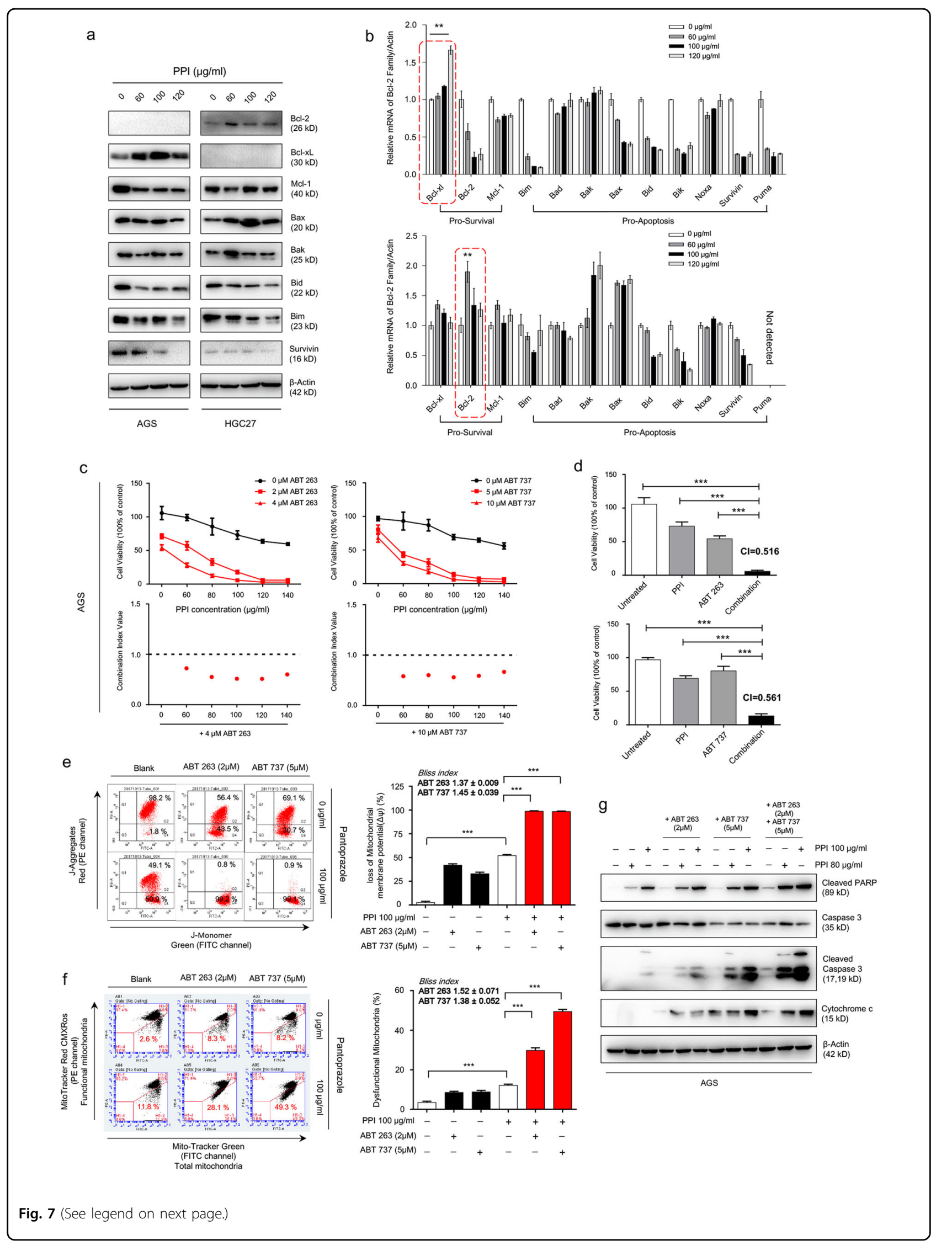




\begin{abstract}
(see figure on previous page)
Fig. 7 Bcl-2 inhibitors synergized the cytotoxicity of PPI. $\mathbf{a}$, b The Bcl-2 family members were analyzed by western blot (a) and qRT-PCR (b). Data were presented as mean $\pm S D\left({ }^{*} p<0.01\right.$, for each gene using one-way ANOVA with Dunnett's multiple comparisons test). c AGS cells were pretreated with various concentrations of PPI for $24 \mathrm{~h}$ in pH 7.4 condition, and then incubated with two different doses of ABT-263/ABT-737 for another $24 \mathrm{~h}$. Data were presented as percentages of cell viability as determined by CCK8 assays (upper panel). Synergisms of cell viability inhibition by the combination therapy were analyzed by Combination Index Value (lower panel). $\mathbf{d}$ Cell viability of AGS cells after treatment with combination of $100 \mu \mathrm{g} / \mathrm{ml} \mathrm{PPI}$ and $4 \mu \mathrm{M}$ ABT-263/10 $\mu \mathrm{M}$ ABT-737 in pH 7.4 condition. The combination indexes (Cl) were calculated as described in Methods section. Data were presented as mean \pm SD $\left({ }^{* * *} p<0.001\right.$, indentified by one-way ANOVA Dunnett's multiple comparison test). e AGS cells were treated as described in (c), and the changes in mitochondrial membrane potential $(\Delta \psi \mathrm{m})$ were analyzed by JC-1 assay. Ratio of green to red fluorescence was depicted (left panel). Data were representative of three independent experiments. Right panel showed the quantification of the $\triangle \psi m$ in AGS cells upon combinational treatment. Data were presented as mean \pm SD ( ${ }^{* * *} p<0.001$, indentified by one-way ANOVA Tukey's multiple comparisons test). f AGS cells were treated as described in (c), and then stained with MitoTracker green (100 nM) and MitoTracker red (400 nM). The dysfunctional mitochondria accumulation was analyzed by FACS. Dot plots of subpopulation are depicted (left panel) and percent of dysfunctional mitochondria were shown as mean \pm SD (right panel) ${ }^{* * *} p<0.001$, indentified by one-way ANOVA Tukey's multiple comparisons test). $\mathbf{g}$ AGS cells were treated as described in (c). The apoptosis related proteins were detected
\end{abstract}

$1.5 \mathrm{ml}$ EP tubes. $1.6 \mathrm{ml}$ of cell suspension including $30 \times 10^{4}$ cells in complete growth medium without antibiotics was first added into each well of six-well plate. After incubation for $20 \mathrm{~min}$ at room temperature, the siRNA-lipid complex was then added gently into cells in a spiral pattern. This gave a final siRNA working concentration of $50 \mathrm{nM}$.

\section{Western blot analysis and antibodies}

Cells were lysed in RIPA buffer (Beyotime Biotechnology, P0013B) containing EDTA-free protease inhibitor cocktail (Roche, 04693159001) on ice for $30 \mathrm{~min}$, and then centrifuged for $15 \mathrm{~min}\left(13,000 \times g, 4{ }^{\circ} \mathrm{C}\right)$. The supernatant was collected, and protein concentrations were determined by BCA Protein Assay Kit (KeyGEN BioTECH, KGP903). Equal amounts of protein (at least $30 \mu \mathrm{g}$ ) were separated on $8-12 \%$ SDS-PAGE and then electrophoretically transferred onto a PVDF membrane (Millipore, Bedford, MA, USA). After blocking with 5\% nonfat milk in Tris-buffered saline containing $0.1 \%$ Tween- 20 for $2-4 \mathrm{~h}$, the membranes were incubated with specific primary antibodies according to the instructions overnight at $4{ }^{\circ} \mathrm{C}$, followed by incubation with appropriate horseradish peroxidase-conjugated secondary antibodies (1:3000 dilutions) for $2 \mathrm{~h}$. Signals generated by enhanced chemiluminescence (Millipore) were recorded by Tanon 4600 imaging system (Tanon, Shanghai, China). Data are representative of at least three independent experiments.

All primary antibodies used in this study were diluted according to the instructions. The catalogue numbers and manufacturers were described in Supplementary Table 2.

\section{Transmission electron microscopy}

Cells were seeded in $75 \mathrm{~cm}^{2}$ cell culture flasks (Corning, $430641)$ at $5 \times 10^{6}$ cells/flask. PPI $(120 \mu \mathrm{g} / \mathrm{ml})$ was added to the flasks on the following day. After $48 \mathrm{~h}$ treatment, cells were collected and fixed with $2.5 \%$ glutaraldehyde in $0.1 \mathrm{M}$ sodium dihydrogen phosphate $(\mathrm{pH}$ 7.4). The samples were then fixed with $1 \% \mathrm{OsO}_{4}$ in $0.1 \mathrm{M}$ cacodylate buffer ( $\mathrm{pH} 7.2)$ containing $0.1 \% \mathrm{CaCl}_{2}$ for $1 \mathrm{~h}$, dehydrated through a graded series of ethanol (30-100\%), and gradually infiltrated with epoxy resin (GENMED, GMS11012). Ultra-thin sections were obtained and stained with $4 \%$ uranyl acetate and lead citrate, and examined in a transmission electron microscope (JEM200CX, JEOL, Japan).

\section{Immunofluorescence}

The pBABE-puro-EGFP-LC3 plasmid was transiently transfected in AGS and HeLa cells. After $48 \mathrm{~h}$ of transfection, the cells underwent designated treatments for further experiments. The GFP-LC3B dots were observed and captured under cellSens fluorescence microscope (Olympus, Tokyo, Japan). The average number of GFP-LC3B dots per cell was determined from three independent experiments. AGS cells were grown on collagen-precoated glass coverslips directly in 24-well plates. After appropriate treatments, cells were fixed with $4 \%$ paraformaldehyde, permeabilized with $0.1 \%$ Triton X100 , blocked with $10 \%$ normal goat serum for $1 \mathrm{~h}$, incubated with indicated primary antibodies and subsequently corresponding Alexa Fluor-labeled secondary antibodies, mounted using the Prolong Gold Antifade reagent with DAPI (Sigma), and viewed using a cellSens fluorescence microscope.

\section{Live-cell imaging for autophagic flux}

The mRFP-GFP-LC3 adenoviral particles were purchased from HanBio (Shanghai, China). Cells $\left(10 \times 10^{4}\right.$ cells per well) were seeded into 6-well plates and then allowed for adherence overnight at $37^{\circ} \mathrm{C}$. Then cells were infected with adenoviral particles at a MOI of 100 in complete medium without antibiotics; after infection for $24 \mathrm{~h}$, the medium was replaced with fresh medium with antibiotics, and the cells were cultured for another $24 \mathrm{~h}$ before various treatments. Imaging was performed on a 


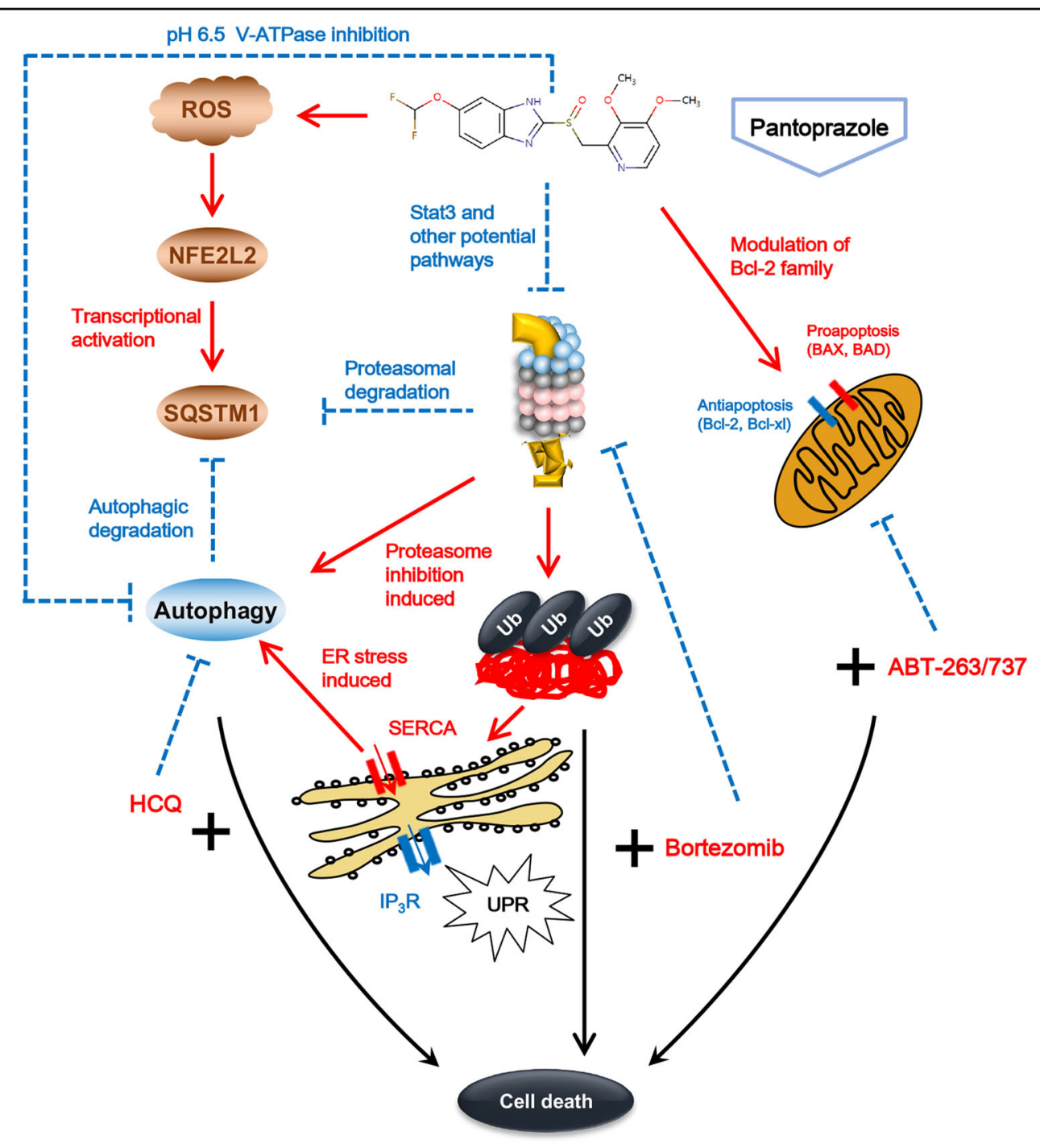

Fig. 8 Schematic illustration of proposed mechanisms. PPI inhibited proteasome function, and induced SQSTM1 elevated autophagy as a compensatory response for impaired proteasomal degradation. PPI promotes autophagic flux in neutral pH condition while blocks autophagic flux in low pH condition. When cancer cells were under proteins overload stress caused by proteasome inhibitors and autophagic flux blockers, or mitochondrial stress caused by Bcl-2 inhibitors, the cytotoxicity of PPI would be significantly increased

Leica SP8 Confocal System (Carl Zeiss, Germany). All image acquisition settings were kept same.

\section{Quantitative real-time PCR with reverse transcription (qRT-PCR)}

After designated treatments, total RNA was isolated from cells using RNAiso Plus Reagent (Takara, 9109). Approximately $1000 \mathrm{ng}$ RNA was reversely transcribed into cDNAs using $5 \times$ PrimeScript RT Master Mix (Takara, RR036A) in a $10 \mu \mathrm{l}$ reaction mixture. The reaction conditions were: $37^{\circ} \mathrm{C}$ for $15 \mathrm{~min}, 85^{\circ} \mathrm{C}$ for $5 \mathrm{~s}$. Quantification of gene expression was performed using the SYBR Premix Ex TaqTM II kit (TaKaRa, Kyoto, Japan) on the LightCycler 96 system (Roche, Mannheim,
Germany). The reaction conditions were: $95^{\circ} \mathrm{C}$ for $10 \mathrm{~min}$, followed by 40 cycles of $95^{\circ} \mathrm{C}$ for $15 \mathrm{~s}$ and $60^{\circ} \mathrm{C}$ for $1 \mathrm{~min}$. All reactions were performed in triplicate. Primers used in real-time PCR experiments were shown in Supplementary Table 3.

\section{Detection of cell death}

Cells were seeded in a six-well plate at a density of $30 \times$ $10^{4}$ cells per well, and then exposed to appropriate treatments for indicated times. The cell death was quantitatively and qualitatively analyzed by the following approaches: (1) PI staining (BD Biosciences, 556463) assay by FACS according to the manufacturer's protocol; (2) the level of PARP and caspase- 3 cleavages were detected by 
western blotting. Both the floating and adherent cells were collected, and then washed twice with phosphate buffered saline (PBS). After harvested, cells were immediately resuspended in $300 \mu \mathrm{l}$ PBS buffer followed by incubation with propidium iodide (PI; final concentration of $5 \mu \mathrm{g} / \mathrm{ml}$ ) for $10 \mathrm{~min}$. The percentage of PI-positive cells, in the name of dead cells, was quantified by BD Accuri ${ }^{\mathrm{Tm}}$ C6 (BD, Becton, Dickinson, USA).

\section{JC-1 assay}

AGS and HGC27 cells were pretreated with PPI for 24 $\mathrm{h}$, and then incubated with or without $\mathrm{Bcl}-2$ inhibitors (ABT-263 or ABT-737) for another 24h. Adherent cells were digested by trypsin and collected with floating cells. Harvested cells was washed twice with PBS, and then incubated with JC- 1 dye for $25 \mathrm{~min}$ at $37^{\circ} \mathrm{C}$. The cells with loss of mitochondrial membrane potential $(\Delta \psi \mathrm{m})$, which showed decreased red fluorescent J-aggregates, were detected by BD FACSAria II (BD, Becton, Dickinson, USA). Data were analyzed by FlowJo software (Version 7.6.5, Tree Star Inc., Ashland, Oregon).

\section{LysoTracker Red staining}

After the planned treatments, cells were harvested and incubated with $50 \mathrm{nM}$ LysoTracker Red DND-99 (LTR, L7528) in PBS for 30 min to label acidic organelles in live cells. After twice washing, cells were suspended in PBS and transferred into $1.5 \mathrm{ml} \mathrm{EP}$ tubes. The fluorescence intensities of at least 10,000 cells/sample were measured by BD FACSAria II (BD, Becton, Dickinson, USA).

\section{Dysfunctional mitochondria labeling}

For labeling mitochondria, the cells were incubated with $100 \mathrm{nM}$ MitoTracker Green FM (total mitochondria) and $400 \mathrm{nM}$ MitoTracker Red CMXRos (functional mitochondria) for $25 \mathrm{~min}$ at $37^{\circ} \mathrm{C}$. The labelled cells were then washed twice with PBS followed by resuspended in PBS for flow cytometry. The subpopulation was distinguished by BD Accuri ${ }^{\text {mi }}$ C6 (BD, Becton, Dickinson, USA). Dysfunctional mitochondria was reflected by decreased red fluorescence intensity under the same green fluorescence intensity $^{47}$.

\section{Statistical analysis}

All data from western blot and flow cytometry analysis were representative of at least three independent experiments. Data were analysed with GraphPad Prism 6 Software to generate curves and bar charts. Statistical analyses were performed using Student $t$ test (two tailed) or ANOVA (analysis of variance). The appropriate tests for multiple comparisons in ANOVA were specifically described in the corresponding Figure legends. ${ }^{*} p<0.05,{ }^{* * *} p<0.01$, and ${ }^{* * * *} p$ $<0.001$ were all considered statistically significant, while $p>$ 0.05 was considered not significant (n.s).

\section{Acknowledgements}

We thank Dr. Hongli Yan, Dr. Min Chen, Dr. Mingming Zhang, and Dr. Xiwei Ding for study design. We thank Dr. Hongli Yan for scientific advice about specific details. We thank Dr. Xiwei Ding for kindly technical help for CalcuSyn software, and scientific advice. We thank Dr. Fan Zhou and Dr. Shu Zhang for helping carry out experiments, process data and prepare manuscript. This study was supported by grants from the National Natural Science Foundation of China (Grant Nos. 81401977 and 81672935), the Jiangsu Clinical Medical Center of Digestive Disease (Grant No. BL2012001).

\section{Author details}

${ }^{1}$ Department of Gastroenterology, Drum Tower Hospital Affiliated to Medical School of Nanjing University, Nanjing, Jiangsu Province, China. ${ }^{2}$ Jiangsu Clinical Medical Center of Digestive Disease, Nanjing, China. ${ }^{3}$ Department of Laboratory Medicine, Changhai Hospital, the Second Military Medical University, Shanghai, China. ${ }^{4}$ Department of General Surgery, Drum Tower Hospital, Medical School of Nanjing University, Nanjing, Jiangsu Province, China. ${ }^{5}$ Department of General Surgery, Drum Tower Clinical College of Nanjing Medical University, Nanjing, Jiangsu Province, China

\section{Author contributions}

X.Z., Y.C., and L.W. designed the study; Y.C., M.C., and D.T. did the cell experiments; Y.C., F.Z., M.Z., and S.Z. performed the western blot analysis; Y.C., X.D., G.X., and W.Z. carried out flow cytometry analysis. H.Y., L.W., and X.Z. provided the facilities for experiments, made suggestions on the performance of experiments. Y.C. and X.Z. prepared the final manuscript. All authors have read and approved the final manuscript.

Conflict of interest

The authors declare that they have no conflict of interest.

\section{Publisher's note}

Springer Nature remains neutral with regard to jurisdictional claims in published maps and institutional affiliations.

Supplementary Information accompanies this paper at (https://doi.org/ 10.1038/s41419-018-0642-6).

Received: 3 December 2017 Revised: 12 April 2018 Accepted: 18 April 2018 Published online: 22 May 2018

\section{References}

1. Kaushik, S. \& Cuervo, A. M. Chaperone-mediated autophagy: a unique way to enter the lysosome world. Trends Cell Biol. 22, 407-417 (2012).

2. Dikic, I. Proteasomal and autophagic degradation systems. Annu. Rev. Biochem. 86, 193-224 (2017).

3. Korolchuk, V. I., Menzies, F. M. \& Rubinsztein, D. C. Mechanisms of cross-talk between the ubiquitin-proteasome and autophagy-lysosome systems. FEBS Lett. 584, 1393-1398 (2010).

4. Milan, E. et al. A plastic SQSTM1/p62-dependent autophagic reserve maintains proteostasis and determines proteasome inhibitor susceptibility in multiple myeloma cells. Autophagy 11, 1161-1178 (2015).

5. Kageyama, S. et al. Proteasome dysfunction activates autophagy and the Keap1-Nrf2 pathway. J. Biol. Chem. 289, 24944-24955 (2014).

6. Demishtein, A. et al. SQSTM1/p62-mediated autophagy compensates for loss of proteasome polyubiquitin recruiting capacity. Autophagy 13, 1697-1708 (2017).

7. Katsuragi, Y., Ichimura, Y. \& Komatsu, M. p62/SQSTM1 functions as a signaling hub and an autophagy adaptor. FEBS J. 282, 4672-4678 (2015).

8. Klionsky, D. J. et al. Guidelines for the use and interpretation of assays for monitoring autophagy (3rd edition). Autophagy 12, 1-222 (2016).

9. Barth, S., Glick, D. \& Macleod, K. F. Autophagy: assays and artifacts. J. Pathol. 221, 117-124 (2010).

10. Obeng, E. A. et al. Proteasome inhibitors induce a terminal unfolded protein response in multiple myeloma cells. Blood 107, 4907-4916 (2006). 
11. Szokalska, A. et al. Proteasome inhibition potentiates antitumor effects of photodynamic therapy in mice through induction of endoplasmic reticulum stress and unfolded protein response. Cancer Res. 69, 4235-4243 (2009).

12. Czabotar, P. E., Lessene, G., Strasser, A. \& Adams, J. M. Control of apoptosis by the BCL-2 protein family: implications for physiology and therapy. Nat. Rev. Mol. Cell Biol. 15, 49-63 (2014).

13. Fennell, D. A., Chacko, A. \& Mutti, L. BCL-2 family regulation by the $20 \mathrm{~S}$ proteasome inhibitor bortezomib. Oncogene 27, 1189-1197 (2008).

14. Delgado, M. E., Dyck, L., Laussmann, M. A. \& Rehm, M. Modulation of apoptosis sensitivity through the interplay with autophagic and proteasomal degradation pathways. Cell Death Dis. 5, e1011 (2014).

15. Perez-Galan, P. et al. BCL-2 phosphorylation modulates sensitivity to the $\mathrm{BH} 3$ mimetic GX15-070 (Obatoclax) and reduces its synergistic interaction with bortezomib in chronic lymphocytic leukemia cells. Leukemia 22, 1712-1720 (2008).

16. Paoluzzi, L. et al. The BH3-only mimetic ABT-737 synergizes the antineoplastic activity of proteasome inhibitors in lymphoid malignancies. Blood $\mathbf{1 1 2}$ 2906-2916 (2008)

17. Dasmahapatra, G. et al. Obatoclax interacts synergistically with the irreversible proteasome inhibitor carfilzomib in GC- and ABC-DLBCL cells in vitro and in vivo. Mol. Cancer Ther. 11, 1122-1132 (2012).

18. De Milito, A. et al. Proton pump inhibitors induce apoptosis of human B-cell tumors through a caspase-independent mechanism involving reactive oxygen species. Cancer Res. 67, 5408-5417 (2007)

19. Marino, M. L. et al. Proton pump inhibition induces autophagy as a survival mechanism following oxidative stress in human melanoma cells. Cell Death Dis. 1, e87 (2010).

20. Tan, Q. et al. Effect of pantoprazole to enhance activity of docetaxel against human tumour xenografts by inhibiting autophagy. Br. J. Cancer 112, 832-840 (2015).

21. Udelnow, A. et al. Omeprazole inhibits proliferation and modulates autophagy in pancreatic cancer cells. PLOS ONE 6, e20143 (2011).

22. Chueca, E. et al. Proton pump inhibitors display antitumor effects in Barrett's adenocarcinoma cells. Front. Pharmacol. 7, 452 (2016).

23. De Milito, A. et al. pH-dependent antitumor activity of proton pump inhibitors against human melanoma is mediated by inhibition of tumor acidity. Int. J. Cancer 127, 207-219 (2010).

24. Canitano, A., lessi, E., Spugnini, E. P., Federici, C. \& Fais, S. Proton pump inhibitors induce a caspase-independent antitumor effect against human multiple myeloma. Cancer Lett. 376, 278-283 (2016).

25. Chen, M. et al. Reversal effects of pantoprazole on multidrug resistance in human gastric adenocarcinoma cells by down-regulating the V-ATPases/ mTOR/HIF-1alpha/P-gp and MRP1 signaling pathway in vitro and in vivo. J. Cell. Biochem. 113, 2474-2487 (2012).

26. Zhang, B. et al. Proton pump inhibitor pantoprazole abrogates adriamycinresistant gastric cancer cell invasiveness via suppression of Akt/GSK-beta/betacatenin signaling and epithelial-mesenchymal transition. Cancer Lett. 356, 704-712 (2015)

27. Lamb, C. A., Yoshimori, T. \& Tooze, S. A. The autophagosome: origins unknown, biogenesis complex. Nat. Rev. Mol. Cell Biol. 14, 759-774 (2013).

28. Marino, M. L. et al. Autophagy is a protective mechanism for human melanoma cells under acidic stress. J. Biol. Chem. 287, 30664-30676 (2012).

29. Lugini, L. et al. Cannibalism of live lymphocytes by human metastatic but not primary melanoma cells. Cancer Res. 66, 3629-3638 (2006).

30. Sun, L. et al. TM9SF4 is a novel factor promoting autophagic flux under amino acid starvation. Cell Death Differ. 25, 368-379 (2018).

31. Lozupone, F. et al. TM9SF4 is a novel V-ATPase-interacting protein that modulates tumor $\mathrm{pH}$ alterations associated with drug resistance and invasiveness of colon cancer cells. Oncogene 34, 5163-5174 (2015).
32. Fais, S. \& Overholtzer, M. Cell-in-cell phenomena, cannibalism, and autophagy: is there a relationship? Cell Death Dis. 9, 95 (2018).

33. Li, $\mathrm{Y}$. et al. Protein kinase $\mathrm{C}$ controls lysosome biogenesis independently of mTORC1. Nat Cell Biol. 18, 1065-1077 (2016).

34. Jain, A. et al. p62/SQSTM1 is a target gene for transcription factor NRF2 and creates a positive feedback loop by inducing antioxidant response elementdriven gene transcription. J. Biol. Chem. 285, 22576-22591 (2010).

35. Chorley, B. N. et al. Identification of novel NRF2-regulated genes by ChIP-Seq: influence on retinoid X receptor alpha. Nucleic Acids Res. 40, 7416-7429 (2012).

36. Pajares, M. et al. Transcription factor NFE2L2/NRF2 is a regulator of macroautophagy genes. Autophagy 12, 1902-1916 (2016).

37. Peng, $\mathrm{H}$. et al. Ubiquitylation of p62/sequestosome1 activates its autophagy receptor function and controls selective autophagy upon ubiquitin stress. Cell Res. 27, 657-674 (2017).

38. Yang, $H_{\text {, }}$ Chen, D., Cui, O. C. Yuan, X \& Dou, O. P. Celastrol, a triterpene extracted from the Chinese "Thunder of God Vine," is a potent proteasome inhibitor and suppresses human prostate cancer growth in nude mice. Cancer Res. 66, 4758-4765 (2006)

39. Nathan, J. A. et al. Immuno- and constitutive proteasomes do not differ in their abilities to degrade ubiquitinated proteins. Cell 152, 1184-1194 (2013).

40. Kuhn, D. J. et al. Targeted inhibition of the immunoproteasome is a potent strategy against models of multiple myeloma that overcomes resistance to conventional drugs and nonspecific proteasome inhibitors. Blood $\mathbf{1 1 3}$ 4667-4676 (2009).

41. Zhang, X. D. et al. Tight junction protein 1 modulates proteasome capacity and proteasome inhibitor sensitivity in multiple myeloma via EGFR/JAK1/ STAT3 signaling. Cancer Cell 29, 639-652 (2016).

42. Huang, S., Chen, M., Ding, X., Zhang, X. \& Zou, X. Proton pump inhibitor selectively suppresses proliferation and restores the chemosensitivity of gastric cancer cells by inhibiting STAT3 signaling pathway. Int. Immunopharmacol. 17 585-592 (2013).

43. Qiu, B. et al. HIF2alpha-dependent lipid storage promotes endoplasmic reticulum homeostasis in clear-cell renal cell carcinoma. Cancer Discov. 5, 652-667 (2015).

44. Yorimitsu, T., Nair, U., Yang, Z. \& Klionsky, D. J. Endoplasmic reticulum stress triggers autophagy. J. Biol. Chem. 281, 30299-30304 (2006).

45. Bernales, S., McDonald, K. L. \& Walter, P. Autophagy counterbalances endoplasmic reticulum expansion during the unfolded protein response. PLoS Biol. 4, e423 (2006).

46. Driscoll, J. J. \& Chowdhury, R. D. Molecular crosstalk between the proteasome, aggresomes and autophagy: translational potential and clinical implications. Cancer Lett. 325, 147-154 (2012).

47. Meng, G. et al. Multifunctional antitumor molecule 5'-triphosphate siRNA combining glutaminase silencing and RIG-I activation. Int. J. Cancer 134 1958-1971 (2014).

48. Li, X. et al. Simultaneous inhibition of the ubiquitin-proteasome system and autophagy enhances apoptosis induced by ER stress aggravators in human pancreatic cancer cells. Autophagy 12, 1521-1537 (2016).

49. Jarauta, $V$. et al. Inhibition of autophagy with chloroquine potentiates carfilzomib-induced apoptosis in myeloma cells in vitro and in vivo. Cancer Lett. 382, 1-10 (2016)

50. Vogl, D. T. et al. Combined autophagy and proteasome inhibition: a phase 1 trial of hydroxychloroquine and bortezomib in patients with relapsed/refractory myeloma. Autophagy 10, 1380-1390 (2014).

51. Boussemart, L. et al. elF4F is a nexus of resistance to anti-BRAF and anti-MEK cancer therapies. Nature 513, 105-109 (2014).

52. Chou, T. C. Theoretical basis, experimental design, and computerized simulation of synergism and antagonism in drug combination studies. Pharmacol. Rev. 58, 621-681 (2006). 